Aus der Klinik für Allgemeine Innere Medizin

(Chefarzt Prof. Dr. med. P. G. Lankisch)

des Städtischen Klinikums Lüneburg

\title{
Der natürliche Verlauf der akuten Pankreatitis und ihre Progression zur chronischen Pankreatitis
}

\author{
INAUGURAL-DISSERTATION \\ zur Erlangung des Doktorgrades \\ der Medizinischen Fakultät \\ der Georg-August-Universität zu Göttingen
}

vorgelegt von

Nils Breuer

aus Freiburg im Breisgau

Göttingen 2007 
Dekan:

1. Berichterstatter:

2. Berichterstatter/in:

3. Berichterstatter/in:

Tag der mündlichen Prüfung:
Prof. Dr. med. C. Frömmel

Prof. Dr. med. P. G. Lankisch 
1. Einleitung 5

2. Patienten und Methodik 7

2.1. Patienten 7

2.2. Diagnostisches Vorgehen bei Verdacht auf akute Pankreatitis 7

2.2.1. Diagnosekriterien 7

2.2.2. Beurteilung der Ätiologie 9

2.2.3. Beurteilung des Schweregrades 9

2.2.3.1. Letalität 13

2.2.3.2. Diagnostisches Vorgehen bei Verdacht auf chronische Pankreatitis 14

2.2.3.3. Nachuntersuchungen 16

2.2.3.4. Statistische Auswertung 16

2.2.3.5. Ethik-Votum 16

3. Ergebnisse 17

3.1. Ätiologie und Verlauf 17

3.2. Demographische Angaben zu den nachuntersuchten Patienten 19

3.3. Pankreatitisrezidive 20

3.4. Entwicklung einer chronischen Pankreatitis 25

3.5. Risikofaktoren für die Entwicklung einer chronischen Pankreatitis 28

3.6. Spätletalität 30

4. Diskussion 33

4.1. Auswirkungen verschiedener Parameter auf die Verlaufsuntersuchungen nach akuter Pankreatitis $\quad 33$

4.1.1. Ätiologie 33 
4.1.2. Priorität 34

4.1.3. Diagnosestellung 35

4.1.4. Nachuntersuchungen 36

4.1.5. Rezidivrate 36

4.2. Entwicklung einer chronischen Pankreatitis 37

4.2.1. Einfluss eines Alkoholabusus 37

4.2.2. Einfluss eines Nikotinabusus 39

4.3. Letalität 39

4.4. Schlussfolgerung 40

5. Zusammenfassung 41

6. Anhang

Fragebogen zu dem Befinden des Patienten nach der ersten akuten Bauchspeicheldrüsenentzündung 43

$\begin{array}{lll}7 . & \text { Literaturverzeichnis }\end{array}$ 


\section{Einleitung}

Seit langem ist die Frage, ob, wann und unter welchen Bedingungen eine akute Pankreatitis in die chronische Form der Erkrankung übergeht, offen.

Die erste Klassifikation von Marseille 1963 (Sarles 1965) sowie eine Publikation von Sarles (1965) sahen diesen Übergang für möglich, aber selten an: "It is unusual for acute pancreatitis to develop into chronic pancreatitis, but it may occur" (Sarles et al. 1965, S. 545); "Acute pancreatitis rarely progresses towards the chronic form" (Sarles 1965, S. VII). Dabei blieb es auch bei der revidierten Klassifikation von Marseille 1984 (Singer et al. 1985, S. 683): "Acute pancreatitis rarely leads to chronic pancreatitis". Die Pankreatitis-Klassifikation von Marseille-Rom 1988 (Sarles et al. 1989) führte erstmals die Definition einer obstruktiven chronischen Pankreatitis ein, die als Folge einer defekt geheilten akuten Pankreatitis entstehen kann: "Should the necroses involve a segment of the main duct, stenosis may result and lead to duct obstruction into chronic obstructive pancreatitis caudally to the stenosis" (Sarles et al. 1989, S. 641).

Aber auch nach dieser Definition war der Übergang von einer akuten in eine chronische Pankreatitis selten. Weitere Übersichten zu diesem Thema bestätigten dies, allerdings wurden die Faktoren, die den Übergang in die chronische Form begünstigen, noch nicht eindeutig identifiziert (Hanck u. Singer 1997; Klöppel 1999; Lankisch 1999).

Das Städtische Klinikum Lüneburg versorgt als einziges Krankenhaus Stadt und Landkreis Lüneburg. Die Leitung der Medizinischen Abteilung, der späteren Medizinischen Klinik und der jetzigen Klinik für Allgemeine Innere Medizin, lag mehr als 20 Jahre - von November 1986 bis Juni 2007 - in den gleichen Händen. Von Anfang an gab es klinikeigene Richtlinien zur Untersuchung von Patienten mit akuter Pankreatitis und zur Definition einer chronischen Pankreatitis. Diese Situation ermöglichte eine epidemiologische Untersuchung zur Frage nach 
Ursache und Schweregrad der akuten Pankreatitis und des Übergangs dieser Erkrankung in die chronische Form.

Ziel dieser Untersuchung war es also, festzustellen:

1. Wie oft kommt es im Anschluss an eine erste akute Pankreatitis zur Entwicklung einer chronischen Pankreatitis?

2. Ist dieser Übergang abhängig von

- Ätiologie bzw. Schweregrad der ersten akuten Pankreatitis?

- Rezidivrate der akuten Pankreatitis?

- Nikotinkonsum bzw. Alkoholkonsum des Patienten?

Antworten zu diesen Fragen könnten gegebenenfalls Hinweise darauf geben, wie eine chronische Pankreatitis zu verhindern ist. 


\section{Patienten und Methodik}

\subsection{Patienten}

Die Untersuchung umfasst 532 Patienten, die vom 01.01 .1987 bis 31.12.2004 mit der Diagnose einer ersten akuten Pankreatitis in das Städtische Klinikum Lüneburg zur stationären Aufnahme kamen und ihren Wohnsitz im Stadtgebiet oder Landkreis Lüneburg hatten.

Patienten, bei denen aus der Vorgeschichte frühere Pankreatitiden oder Episoden unklarer Oberbauchbeschwerden bekannt waren bzw. bei denen eine kontrastmittelverstärkte Computertomographie bei Aufnahme oder im späteren Verlauf Zeichen einer chronischen Pankreatitis wie Pankreasparenchymverkalkungen und/oder typische Gangveränderungen aufwiesen, wurden von dieser Untersuchung ausgeschlossen.

Von diesen 532 Patienten waren 289 (54\%) Männer und 243 (46\%) Frauen. Das Durchschnittsalter lag bei $56 \pm 18$ Jahren $(x \pm S D)$.

\subsection{Diagnostisches Vorgehen bei Verdacht auf akute Pankreatitis}

\subsubsection{Diagnosekriterien}

Die Diagnose einer akuten Pankreatitis wurde klinisch aufgrund der charakteristischen Schmerzsymptomatik und des Untersuchungsbefundes sowie eines Amylase- bzw. Lipaseanstiegs im Serum gestellt. Bei allen Patienten wurden bei Aufnahme bzw. innerhalb der ersten 72 Stunden nach stationärer Aufnahme eine Ultraschalluntersuchung und eine kontrastmittelverstärkte Computertomographie (CT) durchgeführt. Die Einstufung des Computertomogramms wurde nach dem Balthazar-Score (Balthazar et al. 1985, 1990) vorgenommen (Tabelle 1). 
Tabelle 1

Einteilung des Schweregrades einer akuten Pankreatitis nach dem BalthazarScore (Balthazar et al. 1985, 1990)

\begin{tabular}{|c|c|c|}
\hline Stadien & $\begin{array}{l}\text { Punkte- } \\
\text { bewertung }\end{array}$ & Definition \\
\hline A & 0 & Normales Pankreas \\
\hline B & 1 & $\begin{array}{l}\text { Nicht die Organgrenzen überschreitende } \\
\text { Pankreatitis } \\
\text { Segmentäre/diffuse Pankreasvergrößerung mit } \\
\text { Konturunregelmäßigkeiten, inhomogener } \\
\text { Parenchymstruktur, Gangerweiterung, kleinen } \\
\text { intrapankreatischen Flüssigkeitsansammlungen }\end{array}$ \\
\hline $\mathrm{C}$ & 2 & $\begin{array}{l}\text { Die Organgrenzen überschreitende Pankreatitis } \\
\text { wie B, plus Beteiligung des peripankreatischen } \\
\text { Fettgewebes }\end{array}$ \\
\hline$D$ & 3 & $\begin{array}{l}\text { Wie B und } C \text {, plus eine unscharf begrenzte } \\
\text { Flüssigkeitsansammlung }\end{array}$ \\
\hline$E$ & 4 & $\begin{array}{l}\text { Wie B und C, plus zwei unscharf begrenzte } \\
\text { Flüssigkeitsansammlungen und/oder } \\
\text { peripankreatischer Luftnachweis }\end{array}$ \\
\hline $\begin{array}{c}- \\
<33 \% \\
33-50 \% \\
>50 \%\end{array}$ & $\begin{array}{c}0 \\
2 \\
4 \\
6 \\
10\end{array}$ & $\begin{array}{l}\text { Ausmaß der Nekrosen } \\
\text { Keine Nekrosen } \\
\text { Ein Drittel der Drüse nekrotisch } \\
\text { Ein Drittel bis die Hälfte der Drüse nekrotisch } \\
\text { Mehr als die Hälfte der Drüse nekrotisch } \\
\text { Totalnekrose }\end{array}$ \\
\hline
\end{tabular}




\subsubsection{Beurteilung der Ätiologie}

Alkoholismus wurde als Ursache der akuten Pankreatitis angenommen, wenn der Patient oder seine Angehörigen einen regelmäßigen täglichen Alkoholkonsum von mehr als $80 \mathrm{~g}$ reinem Alkohol über mindestens fünf Jahre in Form irgendeines alkoholischen Getränkes angaben oder unmittelbar vor der stationären Aufnahme ein Alkoholexzess stattgefunden hatte.

Eine biliäre Genese wurde beim Nachweis von Gallensteinen, der in der Regel durch Sonographie, Computertomographie oder spätere endoskopisch-retrograde Cholangiopankreatikographie (ERCP) erfolgte, zugrunde gelegt.

Andere Ursachen der akuten Pankreatitis waren Folgen einer ERCPUntersuchung (Post-ERCP-Pankreatitis), Fettstoffwechselstörungen, Lupus erythematodes oder Medikamente, die als Auslöser einer akuten Pankreatitis in Frage kommen können (Mallory u. Kern 1980; Mallory u. Kern 1988; Trivedi u. Pitchumoni 2005).

In allen anderen Fällen galt die Ursache der Erkrankung als unbekannt, so dass die Diagnose einer idiopathischen Pankreatitis gestellt wurde. Eine endoskopische Ultraschalluntersuchung (EUS) wurde bei diesen Patienten nicht durchgeführt. Durch diese Untersuchungsmethode wäre möglicherweise in einzelnen Fällen einer idiopathischen Pankreatitis Gallengrieß festgestellt worden, so dass eine biliäre Pankreatitis hätte diagnostiziert werden können.

\subsubsection{Beurteilung des Schweregrades}

Eine peritoneale Beteiligung bei akuter Pankreatitis wurde angenommen, wenn die Patienten eine generalisierte Abwehrspannung oder einen ebenfalls generalisierten Loslassschmerz (Gummibauch) angaben.

Als ein einzelner prognostischer Parameter diente der Hämatokritwert bei Aufnahme. Ein Wert von $>42,5 \%$ (Lankisch et al. 2001) wurde als 
pathologisch angenommen. Entsprechend der Atlanta-Klassifikation (Bradley III 1993) galten ein Serum-Kreatininwert nach Rehydration von $>2 \mathrm{mg} / \mathrm{dl}$ und ein arterieller Sauerstoffgehalt $\left(\mathrm{pO}_{2}\right)$ von $<60 \mathrm{mmHg}$ als Zeichen einer schweren Pankreatitis.

Zur weiteren Beurteilung des Schweregrades diente der APACHE-II-Score

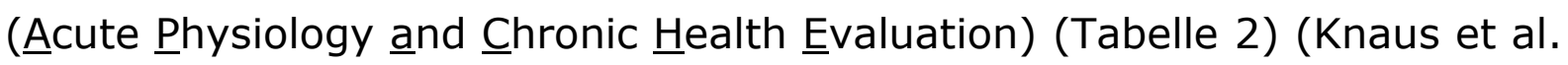
1985) bei Aufnahme und die Bestimmung der prognostischen Parameter nach Ranson (Tabelle 3) (Ranson et al. 1974; Ranson 1982) und Imrie (Tabelle 4) (Blamey et al. 1984) nach 48 Stunden. Entsprechend den Atlanta-Kriterien galten Punktewerte von $>8$ für den APACHE-II-Score, $>3$ für den Ranson-Score und analog dazu $\geq 2$ für den Imrie-Score als Zeichen einer schweren Pankreatitis.

Bei allen Patienten, bei denen eine kontrastmittelverstärkte CT innerhalb der ersten 72 Stunden durchgeführt wurde, erfolgte die Einstufung des Schweregrades der Erkrankung nach dem Balthazar-Score (Tabelle 1, S. 8). Eine interstitielle akute Pankreatitis bestand, wenn der Score 0-4 Punkte, eine nekrotisierende Form, wenn er $\geq 5$ Punkte betrug. Das Ergebnis einer solchen kontrastmittelverstärkten CT-Untersuchung lag bei $388(77 \%)$ von 501 nachverfolgbaren Patienten vor. Bei den verbleibenden $113(23 \%)$ Patienten ergab die Ultraschalluntersuchung einen pathologischen Befund. 
Tabelle 2

APACHE-II-Score (acute physiology and chronic health evaluation) (Knaus et al. 1985)

\begin{tabular}{|c|c|c|c|c|c|c|c|c|c|}
\hline A. Physiologische Variablen & +4 & +3 & +2 & +1 & \pm 0 & +1 & +2 & +3 & +4 \\
\hline Temperatur rektal $\left({ }^{\circ} \mathrm{C}\right)$ & $\geq 41$ & $39-40,9$ & - & $38,5-38,9$ & $36-38,4$ & $34-35,9$ & $32-33,9$ & $30-31,9$ & $\leq 29,9$ \\
\hline Mittlerer arterieller Druck $(\mathrm{mmHg})$ & $\geq 160$ & $130-159$ & $110-129$ & - & $70-109$ & - & $50-69$ & - & $\leq 49$ \\
\hline Herzfrequenz & $\geq 180$ & $140-179$ & $110-139$ & - & $70-109$ & - & $55-69$ & $40-54$ & $\leq 39$ \\
\hline Atemfrequenz (spontan oder maschinell) & $\geq 50$ & $35-49$ & - & $25-34$ & $12-24$ & $10-11$ & $6-9$ & - & $\leq 5$ \\
\hline $\begin{array}{l}\text { Oxygenierung }(\mathrm{mmHg}) \\
\mathrm{FiO}_{2} \geq 0,5=\mathrm{AaDO}_{2} \\
\mathrm{FiO}_{2}>0,5=\mathrm{PaO}_{2}\end{array}$ & $\begin{array}{c}\geq 500 \\
-\end{array}$ & $\begin{array}{c}350-499 \\
-\end{array}$ & $\begin{array}{c}200-349 \\
-\end{array}$ & - & $\begin{array}{l}<200 \\
>70\end{array}$ & $61-70$ & $\begin{array}{l}- \\
-\end{array}$ & $\stackrel{-}{55-60}$ & $<55$ \\
\hline Arterieller $\mathrm{pH}-$ Wert & $\geq 7,7$ & $7,6-7,69$ & - & $7,5-7,59$ & $7,33-7,49$ & - & $7,25-7,32$ & $7,15-7,24$ & $<7,15$ \\
\hline Serum-Natrium (mmol/l) & $\geq 180$ & $160-179$ & $155-159$ & $150-154$ & $130-149$ & - & $120-129$ & $111-119$ & $\leq 110$ \\
\hline Serum-Kalium (mmol/l) & $\geq 7,0$ & $6,0-6,9$ & - & $5,5--5,9$ & $3,5-5,4$ & $3,0-3,4$ & $2,5-2,9$ & - & $<2,5$ \\
\hline Serum-Kreatinin (mg/dl) & $\geq 3,5$ & $2,0-3,4$ & $1,5-1,9$ & - & $0,6-1,4$ & - & $<0,6$ & - & - \\
\hline Hämatokrit (\%) & $>60$ & - & $50-59,9$ & $46-49,9$ & $30-45,9$ & - & $20-29,9$ & - & $<20$ \\
\hline Leukozyten & $\geq 40000$ & - & $20000-39900$ & $15000-19900$ & $3000-14900$ & - & $1000-2900$ & - & $<1000$ \\
\hline \multicolumn{10}{|l|}{$\begin{array}{l}\text { Glasgow-Coma-Score (GCS) } \\
\text { Wert = } 15 \text { minus aktueller GCS }\end{array}$} \\
\hline $\begin{array}{l}\text { Summe der } 12 \text { individuellen } \\
\text { Variablen }\end{array}$ & & & & & & & & & \\
\hline
\end{tabular}

B. Alterspunkte $\leq 44$ Jahre, 0 Punkte; 45-54 Jahre, 2 Punkte; 55-64 Jahre, 3 Punkte; 65-74 Jahre, 5 Punkte; $\geq 75$ Jahre, 6 Punkte

\section{Punkte für chronische Vorerkrankungen}

Hat ein Patient in der Anamnese schwere vorbestehende Organinsuffizienzen oder ist er immunsupprimiert, so sind 5 Punkte für einen nicht operablen oder notfallmäßig operierten Patienten bzw. 2 Punkte für einen elektiv operierten Patienten hinzuzuzählen

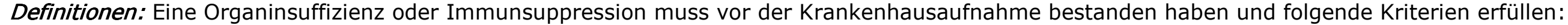

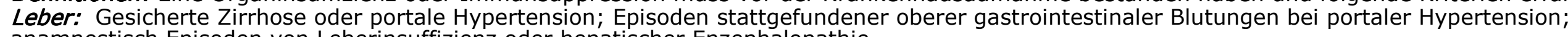

anamnestisch Episoden von Leberinsuffizienz oder hepatischer Enzephalopathie

Herz-Kreislauf: Vor Aufnahme bestandene Herzinsuffizienz Stadium IV NYHA

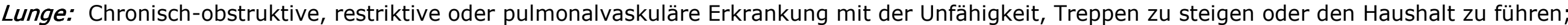
dokumentierte chronische Hypoxie, Hyperkapnie, sekundäre Polyzythämie, schwere pulmonale Hypertension (>40 mmHg)

Niere: Dialysepflichtige Niereninsuffizienz

Immunsystem: Immunsuppression durch Therapien wie Chemotherapie, Radiatio, lang- und hochdosierte Kortisontherapie oder durch

Erkrankungen wie Leukämie, Lymphome, AIDS, etc.

APACHE-II-Score $=$ Summe von A + B + C 
Tabelle 3

Prognostische Parameter nach Ranson (Ranson et al. 1974; Ranson 1982)

\begin{tabular}{|l|c|c|}
\hline Prognostische Parameter & \multicolumn{2}{|c|}{ Akute Pankreatitis } \\
& $\begin{array}{c}\text { Alkoholinduziert, } \\
\text { andere, unbe- } \\
\text { kannte Ursache }\end{array}$ & $\begin{array}{c}\text { Biliär } \\
\text { induziert }\end{array}$ \\
\hline Bei Aufnahme bzw. Diagnosestellung & & \\
1. Alter & $>55 \mathrm{Jahre}$ & $>70 \mathrm{Jahre}$ \\
2. Leukozyten & $>16.000 / \mathrm{mm}^{3}$ & $>18.000 / \mathrm{mm}^{3}$ \\
3. Glukose im Serum & $>200 \mathrm{mg} / \mathrm{dl}$ & $>220 \mathrm{mg} / \mathrm{dl}$ \\
4. Serum-Laktatdehydrogenase (LDH) & $>350 \mathrm{U} / \mathrm{l}$ & $>400 \mathrm{U} / \mathrm{l}$ \\
5. Serum-Glutamat-Oxalazetat-Trans- & $>250 \mathrm{U} / \mathrm{l}$ & $>250 \mathrm{U} / \mathrm{l}$ \\
\multicolumn{1}{|c|}{ aminase (SGOT) } & $>10 \%$ & $>10 \%$ \\
\hline Innerhalb der ersten 48 Stunden & $>5 \mathrm{mg} / \mathrm{dl}$ & $>2 \mathrm{mg} / \mathrm{dl}$ \\
1. Abnahme des Hämatokrits & $<8 \mathrm{mg} / \mathrm{dl}$ & $<8 \mathrm{mg} / \mathrm{dl}$ \\
2. Zunahme des Serum-Harnstoffs & $<60 \mathrm{mmHg}$ & - \\
3. Serum-Kalzium & $>4 \mathrm{mEq} / \mathrm{l}$ & $>5 \mathrm{mEq} / \mathrm{l}$ \\
4. Arterieller pO 2 & $>6 \mathrm{I}$ & $>4 \mathrm{I}$ \\
5. Basendefizit & & \\
6. Geschätzte Flüssigkeitssequestration & & \\
\hline
\end{tabular}


Tabelle 4

Prognostische Parameter nach Imrie (Glasgow-Kriterien) (Imrie et al. 1978)

\begin{tabular}{|l|c|}
\hline Prognostische Parameter & Glasgow-Kriterien \\
\hline 1. Alter & $>55 \mathrm{Jahre}$ \\
2. Leukozyten & $>15 \times 10^{9} / \mathrm{l}$ \\
3. Arterieller $\mathrm{pO}_{2}$ & $<60 \mathrm{~mm} \mathrm{Hg}$ \\
4. Glukose im Serum & $>10 \mathrm{mmol} / \mathrm{l}$ \\
$\quad$ (kein Diabetes in der Vorgeschichte) & \\
5. Harnstoff & $>16 \mathrm{mmol} / \mathrm{l}$ \\
$\quad$ (keine Änderung trotz intravenöser & \\
$\quad$ Flüssigkeitssubstitution) & $<2 \mathrm{mmol} / \mathrm{l}$ \\
6. Serum-Kalzium & $<32 \mathrm{~g} / \mathrm{l}$ \\
7. Serum-Albumin & $>600 \mu \mathrm{g} / \mathrm{l}$ \\
8. Serum-Laktatdehydrogenase & $>100 \mu \mathrm{g} / \mathrm{l}$ \\
9. Serum-Transaminasen & \\
$\quad$ (Serum-Glutamat-Oxalazetat- & \\
Transaminase [SGOT] und & \\
$\quad$ Serum-Glutamat-Pyruvat- & \\
Transaminase [SGPT]) & \\
\hline
\end{tabular}

\subsubsection{Letalität}

Wenn die Erkrankung einen tödlichen Ausgang nahm, wurde untersucht, ob der Tod Folge der akuten Pankreatitis war oder eine andere Ursache hatte. 


\subsubsection{Diagnostisches Vorgehen bei Verdacht auf chronische Pankreatitis}

Die Diagnose einer chronischen Pankreatitis wurde aufgrund morphologischer Kriterien und/oder der Ergebnisse von Funktionsuntersuchungen bzw. bildgebenden Verfahren gestellt. Dieser Score wurde im Städtischen Klinikum Lüneburg 1986 entwickelt und von da an konsequent prospektiv angewandt. Er wurde erstmals 2002 (Lankisch et al. 2002) publiziert und entspricht in etwa dem 1994 veröffentlichten Mayo-Clinic-Score (Layer et al. 1994), beinhaltet aber indirekte Pankreasfunktionstests und den Ultraschall, Verfahren, die in den USA nicht üblich sind (Tabelle 5). Eine chronische Pankreatitis galt nur als bewiesen, wenn eine Punktzahl von $\geq 4$ festgestellt wurde. Nach dieser Punktebewertung konnte somit die Diagnose einer chronischen Pankreatitis nur aufgrund einer Kombination von pathologischen Ergebnissen von Funktionstests und bildgebenden Verfahren gestellt werden. Eine Ausnahme war der Nachweis von Verkalkungen mit irgendeinem Verfahren. Kalk in der Bauchspeicheldrüse gilt als pathognomonisch für eine chronische Pankreatitis.

Zur Beurteilung der exokrinen Pankreasfunktion wurde der Goldstandard, der Sekretin-Cärulein-Test, in einer Modifikation von Creutzfeldt (1964) und Lankisch (2005) durchgeführt. Eine quantitative Stuhlfettanalyse erfolgte mittels des über 72 Stunden gesammelten Stuhls nach Van de Kamer et al. (1949). Die Beurteilung von Ultraschall, CT und ERCP zum Nachweis einer chronischen Pankreatitis wurde nach den CambridgeKriterien (Sarner u. Cotton 1984a, 1984b) vorgenommen. 
Tabelle 5

Diagnose einer chronischen Pankreatitis (CP) nach dem Punktebewertungssystem der Mayo Clinic (Layer et al. 1994) und des Lüneburger Klinikums (Lankisch et al. 2002)

\begin{tabular}{|c|c|c|}
\hline Parameter & $\begin{array}{l}\text { Mayo Clinic- } \\
\text { Score } *^{1}\end{array}$ & $\begin{array}{l}\text { Lüneburg } \\
\text { Score*2 }\end{array}$ \\
\hline $\begin{array}{l}\text { Morphologische Untersuchungen } \\
\text { > Sektionsergebnis einer CP } \\
\text { > Histologischer Befund einer CP } \\
\text { > Intraoperative Befunde, charakteristisch für } \\
\text { eine CP }\end{array}$ & $\begin{array}{r}4 \\
4 \\
\text { n.e. }\end{array}$ & $\begin{array}{l}4 \\
4 \\
4\end{array}$ \\
\hline $\begin{array}{l}\text { Pankreasfunktionstests } \\
>\text { Sekretin-Pankreozymin-Test pathologisch } \\
>\text { Pancreolauryl-Test pathologisch } \\
>\text { Chymotrypsinbestimmung im Stuhl pathologisch } \\
>\text { Elastase-1-Bestimmung im Stuhl pathologisch } \\
>\text { Steatorrhoe }\end{array}$ & $\begin{array}{l}2 \\
\text { n.e. } \\
\text { n.e. } \\
\text { n.e. } \\
2\end{array}$ & $\begin{array}{l}3 \\
2 \\
2 \\
2 \\
1\end{array}$ \\
\hline $\begin{aligned} \text { Bildgebende Verfahren } \\
\text { > Pankreasverkalkungen, nachgewiesen durch } \\
\text { bildgebende Verfahren } \\
>\text { Ultraschall pathologisch } *^{3} \\
>\text { Endoskopischer Ultraschall pathologisch*33 } \\
>\text { Computertomographie pathologisch } *^{3} \\
>\text { ERCP pathologisch }\end{aligned}$ & $\begin{array}{r}4 \\
\text { n.e. } \\
\text { n.e. } \\
\text { n.e. } \\
3\end{array}$ & $\begin{array}{l}4 \\
3 \\
3 \\
3 \\
3\end{array}$ \\
\hline
\end{tabular}

Nach dem Bewertungssystem der Mayo Clinic und des Lüneburger Klinikums: $*^{1} \geq 4$ Bewiesene chronische Pankreatitis, zusätzlich 2 Punkte für $>2$ abgelaufene Pankreatitiden + 1 Punkt für Diabetes mellitus;

$*^{2} \geq 4$ Bewiesene chronische Pankreatitis, 3 vermutlich chronische Pankreatitis;

$*^{3}$ Bei Nachweis von Verkalkungen 4 Punkte;

n.e., nicht erwähnt. 


\subsubsection{Nachuntersuchungen}

Der weitere Krankheitsverlauf wurde anlässlich stationärer Aufenthalte der Patienten im Städtischen Klinikum Lüneburg zur Behandlung von Rezidiven bzw. bei ambulant oder stationär durchgeführten Nachuntersuchungen dokumentiert.

Unabhängig davon wurde allen Patienten ein detaillierter Fragebogen (siehe Anhang, S.43) vorgelegt. Die Fragen bezogen sich vor allem auf die Lebensgewohnheiten vor der ersten akuten Pankreatitis, insbesondere auf den Alkohol- und Zigarettenkonsum, Kriterien, die auch bei der Nachuntersuchung von wesentlicher Bedeutung waren. Des Weiteren wurde nach dem Beschwerdebild gefragt, um gegebenenfalls anhand von abdominellen Schmerzen, Diarrhöen, Entwicklung eines Diabetes, etc. Hinweise auf eine chronische Pankreatitis zu erhalten. Ferner wurde nach späteren Pankreatitisrezidiven, Operationen und sonstigen Erkrankungen gefragt. Alle Angaben wurden gegebenenfalls gemeinsam mit dem Patienten, seinen Angehörigen bzw. Freunden, erhoben, bei verstorbenen Patienten erfolgte eine Befragung der Hausärzte.

\subsubsection{Statistische Auswertung}

Die kumulative Häufigkeit von Rezidiven, der Entwicklung chronischer Pankreatitis sowie der Gesamtletalität wurde nach der Kaplan-MeyerMethode berechnet. Ein Log-Rank-Test verglich die Häufigkeit dieser Ereignisse bei Patienten mit akuter Pankreatitis unterschiedlicher Ätiologie. Zur Berechnung der Überlebenszeit wurde das Datum der stationären Aufnahme wegen einer ersten akuten Pankreatitis bis zum Tod des Patienten oder dem letzten Kontakt mit ihm herangezogen. Alle statistischen Berechnungen waren zweiseitig. Die statistische Analyse wurde mit einer SAS-Software-Version 8 (Cary, NC, USA) durchgeführt. Ein $\mathrm{p}$-Wert $<0,05$ wurde als statistisch signifikant angesehen.

\subsubsection{Ethik-Votum}

Die Studie war von dem Ethik-Komitee der Georg-August-Universität unter der Nummer 22/1/03 genehmigt worden. 


\section{Ergebnisse}

\section{1. Ätiologie und Verlauf}

Als häufigste Ätiologie der akuten Pankreatitis fand sich ein Gallensteinleiden bei 224 (42\%) Patienten. Alkoholabusus war die zweithäufigste Ursache bei 158 (30\%) Patienten. In 44 (8\%) der Fälle wurden andere Ursachen der Erkrankung angenommen. Ungeklärt blieb die Ätiologie bei 106 (20\%) Patienten (Abbildung 1).

Der Anteil der Männer war bei Patienten mit alkoholinduzierter akuter Pankreatitis größer als der der Frauen. Umgekehrt verhielt es sich bei den Patienten mit biliärer Pankreatitis. Das Geschlechterverhältnis war bei den anderen beiden ätiologischen Gruppen ausgewogen. Vergleichbar waren die Nachuntersuchungszeiten für alle ätiologischen Gruppen und die Anzahl der verstorbenen Patienten. Der Anteil der Patienten, bei denen eine Nachuntersuchung nicht möglich war, war höher bei Patienten mit initial alkoholinduzierter akuter Pankreatitis (Abbildung 1).

Nach dem durchschnittlichen Lebensalter bildeten die Patienten mit akuter biliärer Pankreatitis die an Jahren älteste Gruppe, gefolgt von Patienten mit akuter idiopathischer Pankreatitis und Pankreatitis anderer Ätiologie sowie von Patienten mit alkoholinduzierter Pankreatitis. Das durchschnittliche Lebensalter der Patienten mit akuter Pankreatitis biliärer und unbekannter Ätiologie war praktisch gleich, der Abstand zu den Lebensalterpatienten mit akuter Pankreatitis "anderer" und alkoholinduzierter Ätiologie betrug 8-12 bzw. 15-19 Jahre (Abbildung 1). 


\begin{tabular}{|c|c|c|c|c|c|c|c|c|c|c|}
\hline Ätiologie bei erster AP & \multicolumn{2}{|c|}{ Alle Ätiologien } & \multicolumn{2}{|c|}{ Alkohol } & \multicolumn{2}{|c|}{ Biliär } & \multicolumn{2}{|c|}{ Andere } & \multicolumn{2}{|c|}{ Idiopathisch } \\
\hline Patienten mit erster AP & \multicolumn{2}{|c|}{532} & \multicolumn{2}{|c|}{158} & \multicolumn{2}{|c|}{224} & \multicolumn{2}{|c|}{44} & \multicolumn{2}{|c|}{106} \\
\hline Mittleres Alter \pm SD & \multicolumn{2}{|c|}{$56 \pm 18$ Jahre } & \multicolumn{2}{|c|}{$44 \pm 12$ Jahre } & \multicolumn{2}{|c|}{$63 \pm 17$ Jahre } & \multicolumn{2}{|c|}{$51 \pm 19$ Jahre } & \multicolumn{2}{|c|}{$59 \pm 19$ Jahre } \\
\hline Männer (\%) & \multicolumn{2}{|c|}{289 (54\%) } & \multicolumn{2}{|c|}{$134(85 \%)$} & \multicolumn{2}{|c|}{$75(33 \%)$} & \multicolumn{2}{|c|}{24 (55\%) } & \multicolumn{2}{|c|}{$56(53 \%)$} \\
\hline Nachverfolgungszeit* & \multicolumn{2}{|c|}{ 7,8 \pm 5,3 Jahre } & \multicolumn{2}{|c|}{$7,9 \pm 5,4$ Jahre } & \multicolumn{2}{|c|}{ 7,9 \pm 5,3 Jahre } & \multicolumn{2}{|c|}{$7,5 \pm 5,6$ Jahre } & \multicolumn{2}{|c|}{$7,7 \pm 5,2$ Jahre } \\
\hline Tod bei erster AP & \multicolumn{2}{|c|}{$19(4 \%)$} & \multicolumn{2}{|c|}{$6(4 \%)$} & \multicolumn{2}{|c|}{$8(4 \%)$} & \multicolumn{2}{|c|}{$1(2 \%)$} & \multicolumn{2}{|c|}{$4(4 \%)$} \\
\hline $\begin{array}{l}\text { Nicht nachzuverfolgende } \\
\text { Patienten }\end{array}$ & \multicolumn{2}{|c|}{$12(2 \%)$} & \multicolumn{2}{|c|}{$8(5 \%)$} & \multicolumn{2}{|c|}{$2(1 \%)$} & \multicolumn{2}{|c|}{$0(0 \%)$} & \multicolumn{2}{|c|}{$2(2 \%)$} \\
\hline Nachverfolgte Patienten & \multicolumn{2}{|c|}{501} & \multicolumn{2}{|c|}{144} & & & & & & \\
\hline $\begin{array}{l}\text { Rezidive während der } \\
\text { Nachverfolgungszeit }\end{array}$ & $\begin{array}{l}\text { Kein } \\
\text { Rezidiv }\end{array}$ & Rezidiv & $\begin{array}{c}\text { Kein } \\
\text { Rezidiv }\end{array}$ & Rezidiv & $\begin{array}{c}\text { Kein } \\
\text { Rezidiv }\end{array}$ & Rezidiv & $\begin{array}{c}\text { Kein } \\
\text { Rezidiv }\end{array}$ & Rezidiv & $\begin{array}{c}\text { Kein } \\
\text { Rezidiv }\end{array}$ & Rezidiv \\
\hline Patienten & 413 & 88 & 97 & 47 & 189 & 25 & 41 & 2 & 86 & 14 \\
\hline Männer (\%) & $50 \%$ & $68 \%$ & $80 \%$ & $89 \%$ & $33 \%$ & $36 \%$ & $54 \%$ & $50 \%$ & $54 \%$ & $57 \%$ \\
\hline Chronische Pankreatitis & 0 & 19 & 0 & 18 & 0 & 0 & 0 & 1 & 0 & 0 \\
\hline Letalität & $\begin{array}{c}100 \\
(24 \%)\end{array}$ & $\begin{array}{c}24 \\
(27 \%)\end{array}$ & $\begin{array}{c}18 \\
(19 \%)\end{array}$ & $\begin{array}{c}11 \\
(23 \%)\end{array}$ & $\begin{array}{c}49 \\
(26 \%)\end{array}$ & $\begin{array}{c}7 \\
(28 \%)\end{array}$ & $\begin{array}{c}7 \\
(17 \%)\end{array}$ & 0 & $\begin{array}{c}26 \\
(30 \%)\end{array}$ & $\begin{array}{c}6 \\
(43 \%)\end{array}$ \\
\hline
\end{tabular}

*Zeit von erster stationärer Aufnahme bis zum Zeitpunkt des letzten Kontakts oder des Todes

Abb. 1. Nachuntersuchung bei 532 Patienten mit einer ersten akuten Pankreatitis (AP) 


\subsection{Demographische Angaben zu den nachuntersuchten Patienten}

Insgesamt verstarben 19 (4\%) Patienten an den Folgen der ersten akuten Pankreatitis. Hierbei handelte es sich um acht (4\%) Patienten mit biliär induzierter, sechs (4\%) mit alkoholinduzierter und vier (4\%) mit akuter Pankreatitis unbekannter Ätiologie, in der Gruppe mit „anderer" Ätiologie verstarb ein (2\%) Patient (Abbildung 1).

Insgesamt überlebten also 513 Patienten die erste akute Pankreatitis. Davon waren 276 (54\%) Männer und 237 (46\%) Frauen. Das Durchschnittsalter betrug $56 \pm 18(\mathrm{x} \pm \mathrm{SD})$ Jahre. Das Alter der Frauen lag mit $59 \pm 19$ Jahren höher als das der Männer (52 \pm 17 Jahre) (Tabelle 6).

Zwölf (2\%) Patienten hatten entweder den Wohnort so gewechselt, dass sie für eine Befragung nicht erreichbar waren, oder waren nicht bereit, Auskunft zu geben. Also konnten insgesamt 501 (98\%) der 513 Patienten, die die erste akute Pankreatitis überlebt hatten, nachverfolgt werden.

Das Durchschnittsalter dieser 501 Patienten betrug $56 \pm 18$ Jahre. Das durchschnittliche Lebensalter der Frauen lag mit $60 \pm 19$ Jahren über dem der Männer, deren durchschnittliches Lebensalter $53 \pm 17$ Jahre betrug (Tabelle 6). 
Tabelle 6

Demographische Angaben zu den 513 Patienten, die eine erste akute Pankreatitis überlebt haben und nachuntersucht werden konnten

\begin{tabular}{|l|c|c|c|}
\hline Patientendaten & $\begin{array}{c}\text { Patienten } \\
\mathrm{n}(\%)\end{array}$ & $\begin{array}{c}\text { Alter (Jahre) } \\
(\mathrm{x} \pm \mathrm{SD})\end{array}$ & $\begin{array}{c}\text { Bereich } \\
(\text { Jahre })\end{array}$ \\
\hline $\begin{array}{l}\text { Alle Patienten, die eine } \\
\text { erste akute Pankreatitis } \\
\text { überlebt haben }\end{array}$ & $513(100 \%)$ & $56 \pm 18$ & $14-92$ \\
\hline Davon Männer & $276(54 \%)$ & $52 \pm 17$ & $14-92$ \\
\hline Davon Frauen & $237(46 \%)$ & $59 \pm 19$ & $15-89$ \\
\hline $\begin{array}{l}\text { Alle Patienten, die nach- } \\
\text { untersucht werden konnten }\end{array}$ & $501(100 \%)$ & $56 \pm 18$ & $14-92$ \\
\hline Davon Männer & $268(53 \%)$ & $53 \pm 17$ & $14-92$ \\
\hline Davon Frauen & $233(47 \%)$ & $60 \pm 19$ & $15-89$ \\
\hline
\end{tabular}

\subsection{Pankreatitisrezidive}

$\mathrm{Zu}$ einem Rezidiv der Erkrankung kam es bei 88 (21\%) Patienten. Der Anteil der Männer $(n, 60)$ in dieser Gruppe war höher als der der Frauen ( $n, 28 ; 68 \%$ vs. $32 \%$; Abbildung 1 , Tabelle 7 )

Der Geschlechterunterschied war besonders deutlich bei Patienten mit alkoholinduzierter Pankreatitis (89\% Männer vs. 11\% Frauen). Bei Patienten mit biliärer Pankreatitis war es nahezu umgekehrt: 64\% Frauen, 36\% Männer (Abbildung 1). Bei 24 der 25 Patienten mit einem Rezidiv einer biliären akuten Pankreatitis war keine Cholezystektomie nach der Ersterkrankung durchgeführt worden. Die Geschlechterverteilung bei den anderen beiden ätiologischen Gruppen war ausgewogen (Abbildung 1). 
Tabelle 7

Rezidivrate, wenn alle 532 Patienten mit einer ersten akuten Pankreatitis zugrunde gelegt werden, aufgeschlüsselt nach Ätiologie der Erkrankung sowie Alter und Geschlecht der Patienten

\begin{tabular}{|c|c|c|c|c|}
\hline Merkmale & $\begin{array}{l}\text { Anzahl der } \\
\text { Patienten }\end{array}$ & $\begin{array}{c}\text { Personen- } \\
\text { jahre }\end{array}$ & $\begin{array}{c}\text { Patienten mit einem } \\
\text { Rezidiv } \\
(\mathrm{n}[\text { Rate/100/Jahr }])\end{array}$ & $\begin{array}{l}p \text {-Wert } \\
\text { (Log-Rank) }\end{array}$ \\
\hline Alle Patienten & 532 & 3559 & $88(3)$ & \\
\hline $\begin{array}{l}\text { Ätiologie } \\
\text { - Biliär } \\
\text { - Alkohol } \\
\text { - Idiopathisch } \\
\text { - Andere }\end{array}$ & $\begin{array}{l}224 \\
158 \\
106 \\
44\end{array}$ & $\begin{array}{l}1625 \\
886 \\
730 \\
318\end{array}$ & $\begin{array}{r}25(2) \\
47(5) \\
14(2) \\
2(1)\end{array}$ & 0,0001 \\
\hline $\begin{array}{l}\text { Geschlecht } \\
\text { - Männlich } \\
\text { - Weiblich }\end{array}$ & $\begin{array}{l}289 \\
243\end{array}$ & $\begin{array}{l}1874 \\
1684\end{array}$ & $\begin{array}{l}60(3) \\
28(2)\end{array}$ & $0,004 *$ \\
\hline $\begin{array}{l}\text { Alter (Jahre) } \\
\begin{array}{r}<40 \\
40-49 \\
50-59 \\
60-69 \\
\geq 70\end{array}\end{array}$ & $\begin{array}{r}117 \\
85 \\
81 \\
107 \\
142\end{array}$ & $\begin{array}{l}811 \\
552 \\
661 \\
785 \\
749\end{array}$ & $\begin{array}{l}34(4) \\
21(4) \\
10(2) \\
13(2) \\
10(1)\end{array}$ & $<0,0001$ \\
\hline $\begin{array}{l}\text { Nikotinabusus } \\
\text { Nein } \\
\text { Ja } \\
\text { Unbekannt }\end{array}$ & $\begin{array}{r}212 \\
222 \\
98\end{array}$ & $\begin{array}{r}1690 \\
1418 \\
451\end{array}$ & $\begin{array}{l}20(1) \\
52(4) \\
16(4)\end{array}$ & $<0.0001$ \\
\hline
\end{tabular}

*Nicht mehr signifikant nach Anpassung nach Ätiologie

Bei der Aufschlüsselung der Rezidivrate entsprechend der Ätiologie der Erkrankung zeigte sich, dass Patienten mit einer alkoholischen Ätiologie 
signifikant häufiger ein Rezidiv erlitten als die anderen drei ätiologischen Gruppen zusammen (Log-Rank $p<0,0001$; Abbildung 2).

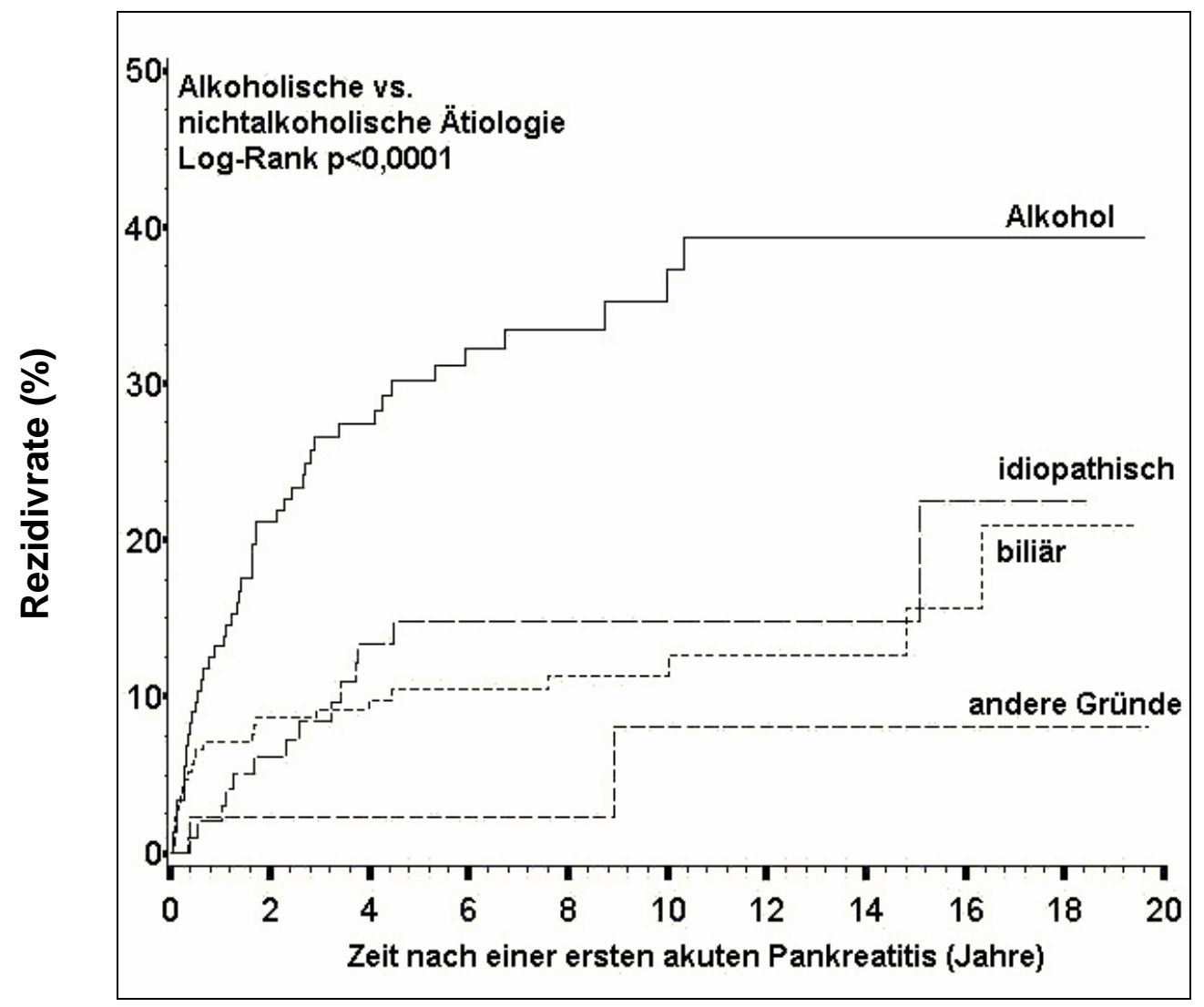

Abb. 2. Rezidivrate nach erster akuter Pankreatitis entsprechend ihrer Ätiologie. Der Unterschied zwischen alkohol- versus nicht alkoholinduzierter Pankreatitis war signifikant; Log-Rank $p<0.0001$.

Bei der detaillierten Aufschlüsselung der Rezidivrate nach Ätiologie der Erkrankung und Alter und Geschlecht der Patienten zeigte sich, dass Patienten mit Alkoholabusus, Männer, Patienten in jüngerem Alter und Raucher ein erhöhtes Risiko hatten, an einem Pankreatitisrezidiv zu erkranken. Eine Multivariat-Analyse ergab jedoch, dass nur Alkoholabusus als Ätiologie und junges Lebensalter unabhängige prognostische Faktoren für die Entwicklung eines Pankreatitisrezidivs waren (Tabelle 7). Die Rezidivrate einer akuten Pankreatitis war unabhängig von dem Schweregrad der Ersterkrankung (Tabelle 8 ). 
Tabelle 8

Pankreatitisrezidivrate bei 501 nachverfolgten Patienten. Die Tabelle enthält keine Angaben zu den 19 Patienten, die bei der Ersterkrankung verstarben bzw. zu den 12 Patienten, die zur Nachuntersuchung nicht zur Verfügung standen oder die nicht bereit waren, Auskünfte zu geben

\begin{tabular}{|c|c|c|c|c|c|c|c|c|c|c|}
\hline & \multirow{2}{*}{$\begin{array}{l}\text { Anzahl } \\
\text { der Pa- } \\
\text { tienten }\end{array}$} & \multirow{2}{*}{$\begin{array}{l}\text { Personen- } \\
\text { Jahre }\end{array}$} & \multirow{2}{*}{$\begin{array}{l}\text { Patienten } \\
\text { mit einem } \\
\text { Rezidiv }\end{array}$} & \multicolumn{4}{|c|}{ Kumulative Rezidivrate in \% (95\% Konfidenzintervall (KI)) } & \multirow{2}{*}{$\begin{array}{l}\text { Log- } \\
\text { Rank }\end{array}$} & \multirow{2}{*}{$\begin{array}{l}\text { Univariat-HR* } \\
(95 \% \mathrm{KI})\end{array}$} & \multirow{2}{*}{$\begin{array}{l}\text { Multivariat-HR* } \\
(95 \% \mathrm{KI})\end{array}$} \\
\hline & & & & $1 \mathrm{Jahr}$ & 2 Jahre & 5 Jahre & 10 Jahre & & & \\
\hline Alle Patienten & 501 & 3564 & 79 & $7(5-9)$ & $10(7-13)$ & $15(12-18)$ & $17(13-21)$ & & & \\
\hline \multicolumn{11}{|c|}{ Nikotinabusus } \\
\hline Nein & 209 & 1690 & 20 & $7(3-10)$ & $8(5-12)$ & $9(5-13)$ & $9(5-13)$ & & Ref & Ref \\
\hline $\mathrm{Ja}$ & 210 & 1424 & 46 & $6(3-10)$ & $12(7-16)$ & $19(13-24)$ & $24(17-30)$ & & $2,51(1,49-4,25)$ & $1,17(0,62-2,21)$ \\
\hline Unbekannt & 82 & 450 & 13 & $9(3-16)$ & $11(4-18)$ & $20(10-30)$ & $20(10-30)$ & 0.0004 & $2,10(1,04-4,23)$ & $2,61(1,25-5,42)$ \\
\hline \multicolumn{11}{|l|}{$\begin{array}{l}\text { Peritonitis- } \\
\text { Zeichen }\end{array}$} \\
\hline Nein & 345 & 2489 & 47 & $7(4-10)$ & $9(6-12)$ & $13(9-17)$ & $15(11-19)$ & & Ref & \\
\hline $\mathrm{Ja}$ & 156 & 1075 & 32 & $7(3-10)$ & $13(7-18)$ & $19(12-25)$ & $21(14-28)$ & 0,062 & $1,53(0,98-2,40)$ & \\
\hline \multicolumn{11}{|l|}{ Hämatokrit } \\
\hline$\leq 42,5 \%$ & 186 & 1243 & 27 & $8(4-12)$ & $11(6-15)$ & $14(9-20)$ & $16(10-21)$ & & Ref & \\
\hline$>42,5 \%$ & 302 & 2203 & 49 & $6(4-9)$ & $10(6-13)$ & $15(11-20)$ & $18(13-23)$ & & $1,07(0,67-1,71)$ & \\
\hline Unbekannt & 13 & 119 & 3 & $8(0-22)$ & $15(0-35)$ & $15(0-35)$ & $15(0-35)$ & 0,78 & $1,35(0,41-4,45)$ & \\
\hline \multicolumn{11}{|l|}{ Kreatinin } \\
\hline$<2 \mathrm{mg} / \mathrm{dl}$ & 473 & 3356 & 75 & $7(5-10)$ & $10(8-13)$ & $15(12-18)$ & $17(13-21)$ & & Ref & \\
\hline$\geq 2 \mathrm{mg} / \mathrm{dl}$ & 14 & 72 & 2 & $7(0-21)$ & $7(0-21)$ & $21(0-47)$ & $21(0-47)$ & & $1,07(0,26-4,34)$ & \\
\hline Unbekannt & 14 & 136 & 2 & - & $8(0-22)$ & $8(0-22)$ & $8(0-22)$ & 0,94 & $0,79(0,20-3,23)$ & \\
\hline \multicolumn{11}{|l|}{$\mathrm{pO}_{2}$} \\
\hline$\geq 60 \mathrm{mmHg}$ & 202 & 1582 & 28 & $5(2-8)$ & $10(5-14)$ & $12(7-17)$ & $13(9-18)$ & & Ref & \\
\hline$<60 \mathrm{mmHg}$ & 18 & 137 & 2 & $6(0-17)$ & $6(0-17)$ & $12(0-29)$ & $12(0-29)$ & & $0,83(0,20-3,47)$ & \\
\hline Unbekannt & 281 & 1845 & 49 & $8(5-12)$ & $11(7-14)$ & $18(13-22)$ & $20(15-25)$ & 0,79 & $1,39(0,87-2,21)$ & \\
\hline
\end{tabular}




\begin{tabular}{|c|c|c|c|c|c|c|c|c|c|}
\hline \multirow{2}{*}{$\begin{array}{l}\text { Fortsetzung } \\
\text { APACHE-II- } \\
\text { Score }\end{array}$} & \multicolumn{9}{|c|}{ Tabelle 8} \\
\hline & & \multirow[b]{2}{*}{2610} & \multirow[b]{2}{*}{63} & \multirow[b]{2}{*}{$8(5-11)$} & \multirow[b]{2}{*}{$12(8-15)$} & \multirow[b]{2}{*}{$17(13-21)$} & \multirow[b]{2}{*}{$19(14-23)$} & \multirow{4}{*}{0,052} & \multirow{4}{*}{$\begin{array}{l}\text { Ref } \\
0,58(0,33-1,02) \\
-\end{array}$} \\
\hline$<8$ Punkte & 344 & & & & & & & & \\
\hline$\geq 8$ Punkte & 155 & 934 & 15 & $5(1-8)$ & $7(3-11)$ & $10(5-15)$ & $12(6-18)$ & & \\
\hline Unbekannt & 2 & 10 & 1 & - & - & - & - & & \\
\hline \multicolumn{10}{|l|}{ Ranson-Score } \\
\hline <3 Punkte & 404 & 2842 & 69 & $8(5-10)$ & $11(8-14)$ & $16(12-20)$ & $19(14-23)$ & & Ref \\
\hline$\geq 3$ Punkte & 81 & 544 & 8 & $4(0-8)$ & $7(1-12)$ & $12(4-20)$ & $12(4-20)$ & 0,17 & $0,60(0,29-1,24)$ \\
\hline Unbekannt & 16 & 178 & 2 & - & - & - & - & & $0,59(0,14-2,41)$ \\
\hline \multicolumn{10}{|l|}{ Imrie-Score } \\
\hline$<2$ Punkte & 287 & 2096 & 54 & $8(5-11)$ & $12(8-16)$ & $18(13-22)$ & $20(15-26)$ & & Ref \\
\hline$\geq 2$ Punkte & 200 & 1297 & 23 & $6(2-9)$ & $8(4-12)$ & $12(7-16)$ & $13(8-18)$ & 0,069 & $0,64(0,39-1,04)$ \\
\hline Unbekannt & 14 & 171 & 2 & - & - & - & - & & $0,59(0,14-2,44)$ \\
\hline \multicolumn{10}{|l|}{$\begin{array}{l}\text { Balthazar- } \\
\text { Score }\end{array}$} \\
\hline$<5$ Punkte & 347 & 2288 & 60 & $8(5-11)$ & $12(8-15)$ & $17(13-21)$ & $18(14-23)$ & & Ref \\
\hline$\geq 5$ Punkte & 41 & 303 & 9 & $10(1-20)$ & $16(4-27)$ & $19(6-31)$ & $19(6-31)$ & & $1,22(0,60-2,46)$ \\
\hline Unbekannt & 113 & 973 & 10 & $2(0-4)$ & $4(0-7)$ & $7(2-11)$ & $12(5-19)$ & 0,58 & $0,43(0,22-0,85)$ \\
\hline
\end{tabular}

*HR, Hazard Ratio; KI, Konfidenzintervall 


\subsection{Entwicklung einer chronischen Pankreatitis}

Eine chronische Pankreatitis entwickelte sich bei 19 (4\%) der 501 Patienten. Von ihnen hatten 18 Patienten primär eine alkoholinduzierte Pankreatitis. Ein Patient, der zunächst eine akute Pankreatitis als Folge eines Lupus erythematodes durchgemacht hatte, begann nach dieser Erkrankung mit einem erheblichen Alkoholabusus, so dass weitere Rezidive als alkoholinduziert eingestuft wurden und er in die Alkoholgruppe aufzunehmen war.

Während der Nachverfolgungszeit wurden Rezidive bei 47 (33\%) der 144 Patienten mit alkoholinduzierter, bei 25 (12\%) der 214 mit biliärer und bei $14(14 \%)$ der 100 Patienten mit idiopathischer Pankreatitis beobachtet. In der Gruppe „andere Ätiologie" erlitten zwei (5\%) von 43 Patienten ein Rezidiv. Rezidive nach einer nicht alkoholinduzierten Erkrankung führten nicht zur Entwicklung einer chronischen Pankreatitis (Tabelle 9).

Tabelle 9

Entwicklung einer chronischen Pankreatitis bei 501 Patienten mit einer ersten akuten Pankreatitis

\begin{tabular}{|l|c|c|c|}
\hline & $\begin{array}{c}\text { Anzahl der } \\
\text { Patienten }\end{array}$ & $\begin{array}{r}\text { Chronische } \\
\text { Pankreatitis }\end{array}$ & $p$-Wert \\
\hline Ätiologie & 144 & $18(13 \%)$ & \\
- Alkohol & 214 & $0 \quad(0 \%)$ & \\
- Biliär & 43 & $0 \quad(0 \%)$ & \\
- Idiopathisch & 100 & $1 \quad(2 \%)$ & $<0,0001$ \\
\hline Alle Patienten & 501 & $19(4 \%)$ & \\
\hline
\end{tabular}


Zwei Patienten, einer mit initial alkoholinduzierter und einer mit initial biliärer akuter Pankreatitis, hatten eine so schwere Erkrankung, dass ausgedehnte Nekrosektomien erforderlich waren. Sie hatten bereits am Ende des ersten stationären Aufenthaltes als Folge der Erkrankung selbst bzw. der notwendigen Operationen eine schwere exokrine Pankreasinsuffizienz. Da sie aber keinerlei morphologische Zeichen einer chronischen Pankreatitis aufwiesen, wurde bei innen ein Folge- bzw. Narbenzustand nach schwerer akuter Pankreatitis angenommen und nicht die Diagnose einer chronischen Pankreatitis gestellt.

Insgesamt lag das Zeitintervall zwischen der ersten Pankreatitis und der Diagnose einer chronischen Pankreatitis bei $3 \pm 7$ Jahren (4 Monate bis 16 Jahre). Die chronische Pankreatitis wurde bei neun Patienten beim ersten, bei sieben beim zweiten und bei drei beim dritten Rezidiv diagnostiziert. Bei dem Patienten mit einem Lupus erythematodes als initiale Ursache der akuten Pankreatitis und späterem Alkoholabusus wurde die chronische Pankreatitis erst bei dem dritten Rezidiv diagnostiziert, das Zeitintervall von der Ersterkrankung bis zum zweiten Rezidiv betrug bei inm sieben Jahre.

Die kumulative Inzidenz einer chronischen (alkoholinduzierten) Pankreatitis betrug $13 \%$ zehn Jahre und $16 \%$ zwanzig Jahre nach der Ersterkrankung (Abbildung 3). 


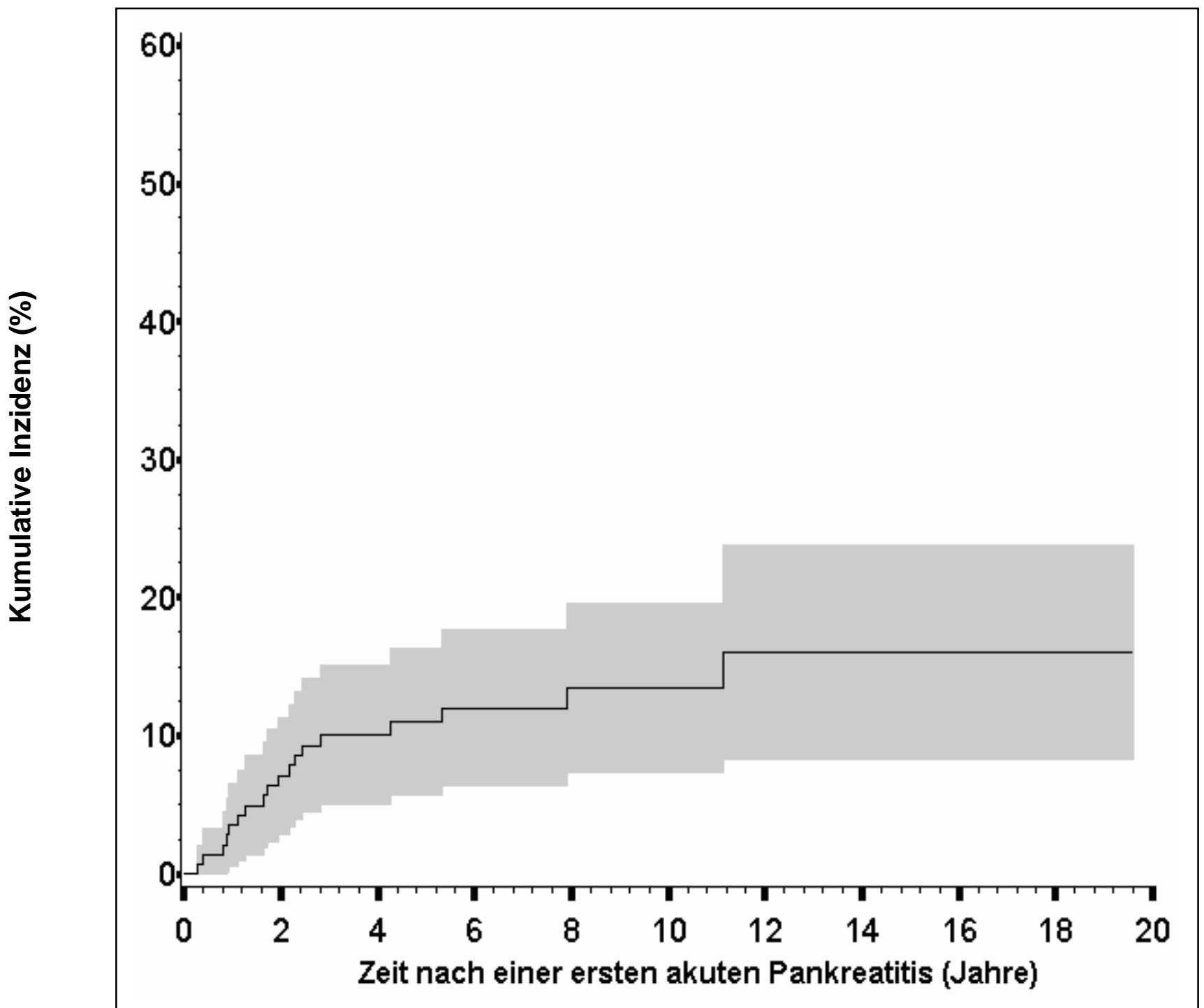

Abb. 3. Kumulative Inzidenz einer chronischen Pankreatitis bei akuter alkoholinduzierter Pankreatitis: 13\% zehn und 16\% 20 Jahre nach der Ersterkrankung. Der schraffierte Bereich entspricht dem 95\%-Konfidenzintervall.

Nach einem ersten Rezidiv stieg die Inzidenz nach bereits zwei Jahren auf $38 \%$ und nach zehn Jahren auf $41 \%$ an (Abbildung 4 ). 


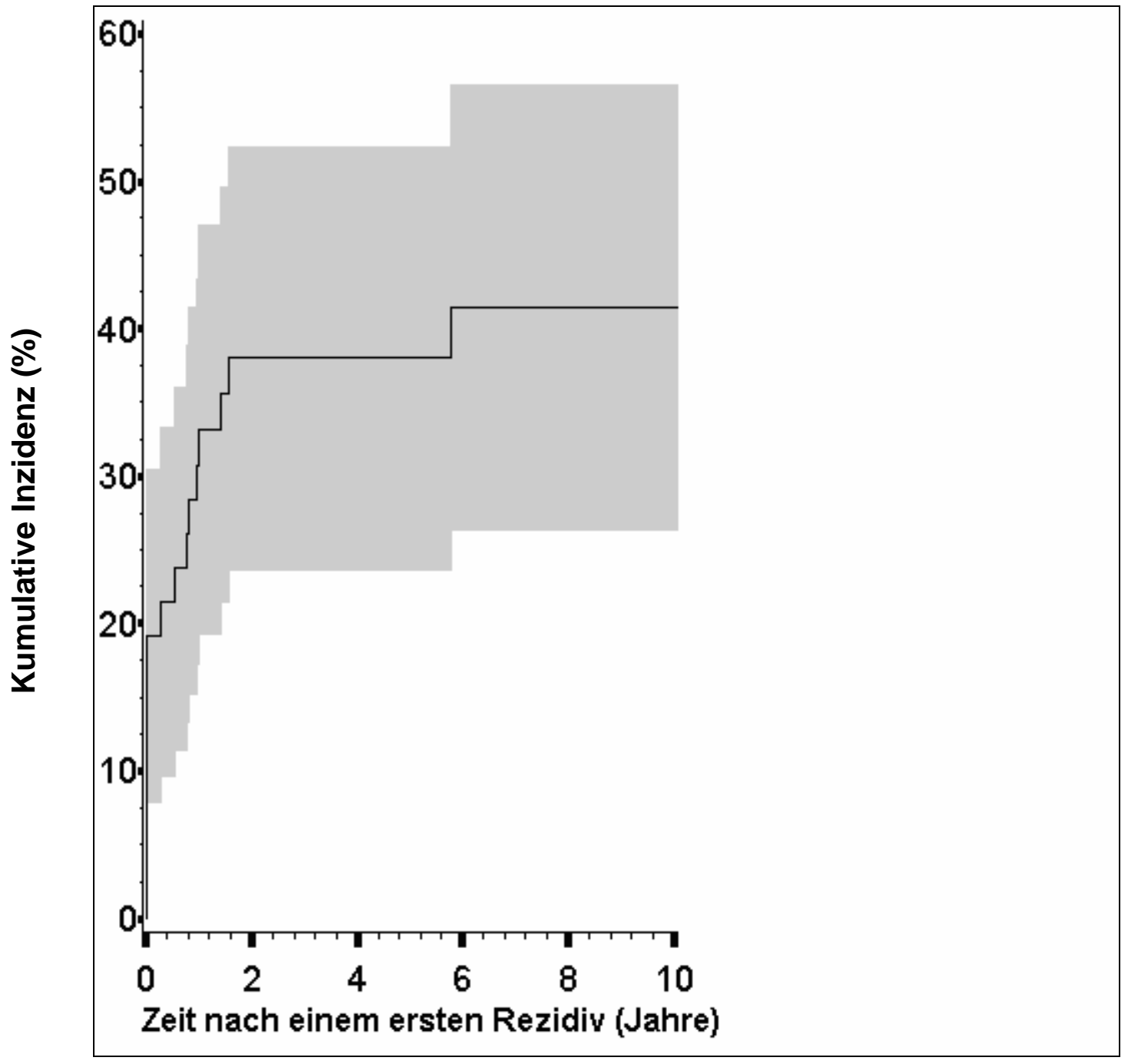

Abb. 4. Kumulative Inzidenz einer chronischen, alkoholinduzierten Pankreatitis nach dem ersten Rezidiv (Jahre) der Erkrankung: 38\% nach zwei und 41\% nach zehn Jahren. Der schraffierte Bereich entspricht dem 95\%-Konfidenzintervall

\subsection{Risikofaktoren für die Entwicklung einer chronischen Pankreatitis}

Das Risiko, eine chronische Pankreatitis zu entwickeln, war bei den 144 Patienten mit einer ersten alkoholinduzierten Pankreatitis unabhängig vom Geschlecht und vom Alter der Patienten sowie auch vom Schweregrad der ersten akuten Pankreatitis (gemessen an einzelnen und multiplen prognostischen Parametern). Ein erhöhter Alkoholkonsum führte ebenso wie ein erhöhter Nikotinabusus vermehrt zur Entwicklung einer chronischen Pankreatitis. Eine Reihe von Patienten hatte allerdings keine genauen Angaben zum Alkohol- und Nikotinkonsum gemacht (Tabelle 10). 
Tabelle 10

Das Risiko, eine chronische Pankreatitis zu entwickeln, bei 144 Patienten mit einer ersten alkoholinduzierten akuten Pankreatitis

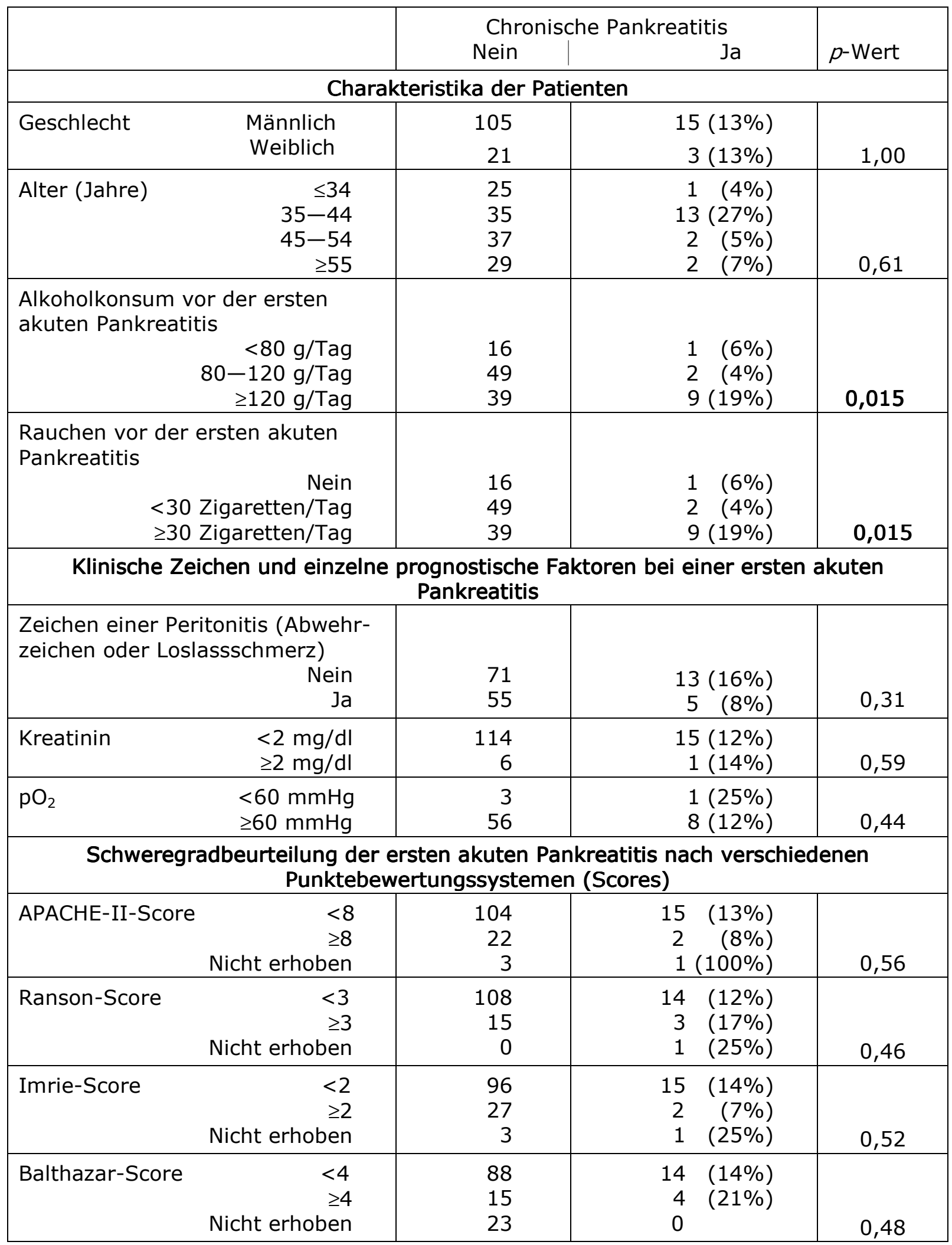




\subsection{Spätletalität}

Insgesamt verstarben 143 Patienten, 19 von innen bereits als Folge der ersten Pankreatitis. Im Verlauf der Beobachtungszeit kamen weitere 124 (25\%) der 501 Patienten zu Tode. Ein Unterschied zwischen den ätiologischen Gruppen bestand nicht (Abbildung 5). Im Einzelnen verstarben 29 Patienten mit alkoholinduzierter ( $n, 144 ; 20 \%), 56$ mit biliär induzierter $(n, 214 ; 26 \%), 32$ mit idiopathischer $(n, 100 ; 32 \%)$ akuter Pankreatitis sowie sieben Patienten aus der Gruppe "andere Ätiologie" ( $n$, 43; 16\%; Abbildung 5; Tabelle 11).

Die einzelnen Todesursachen sind in Tabelle 11 aufgelistet. Auffällig ist, dass vier Patienten an einem Pankreaskarzinom verstarben. Bei einem Patienten wurde das Karzinom innerhalb eines Jahre nach der ersten akuten idiopathischen Pankreatitis diagnostiziert, bei einem anderen Patienten mit alkoholinduzierter akuter Pankreatitis kam es zu mehreren Rezidiven, bevor das Pankreaskarzinom diagnostiziert wurde. Es muss offen bleiben, ob in diesen beiden Fällen die Ursache der akuten Pankreatitis nicht ein kleines, den Pankreasgang einengendes Pankreaskarzinom war. 


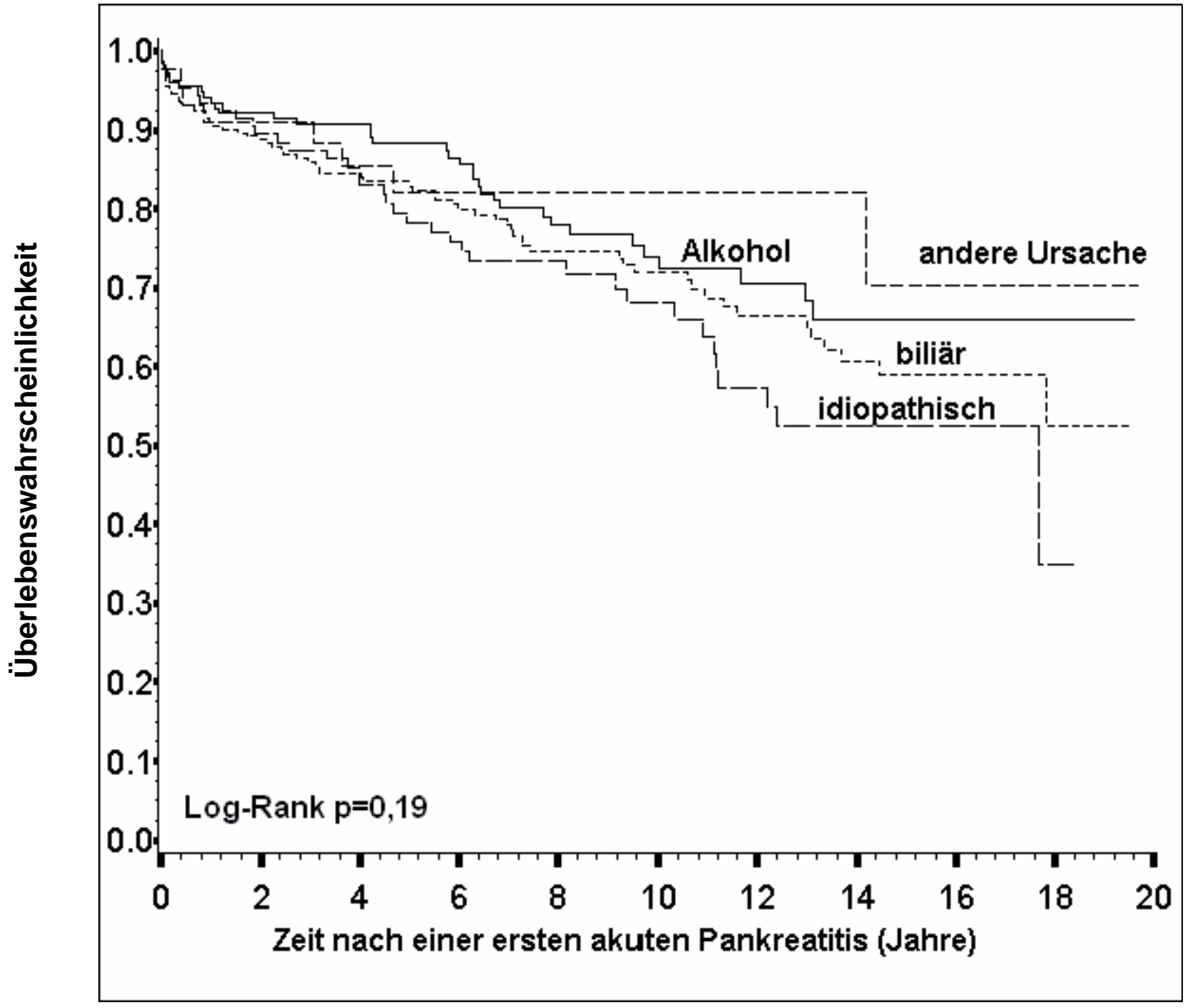

Abb. 5. Gesamtüberlebensrate nach Ätiologien nach einer ersten akuten Pankreatitis. Der Unterschied war nicht signifikant; Log-Rank $p=0,19$. 
Tabelle 11

Letalität bei 532 Patienten nach einer ersten akuten Pankreatitis in Lüneburg von 1987-2004

\begin{tabular}{|l|r|c|c|}
\hline Todesursache & $\begin{array}{l}\text { Letalität } \\
\text { insgesamt }\end{array}$ & $\begin{array}{l}\text { Nicht alko- } \\
\text { holinduzierte } \\
\text { Pankreatitis }\end{array}$ & $\begin{array}{l}\text { Alkoholinduzierte } \\
\text { Pankreatitis }\end{array}$ \\
\hline Letalität insgesamt & 143 & 108 & 35 \\
\hline Pankreatitis* & 29 & 20 & 9 \\
\hline Pankreaskarzinom & 4 & 3 & 1 \\
\hline Andere Karzinome & 24 & 20 & 4 \\
\hline $\begin{array}{l}\text { Kardio-/zerebrovaskuläre } \\
\text { Erkrankungen }\end{array}$ & 59 & 53 & 6 \\
\hline Pulmonale Erkrankungen & 9 & 7 & 2 \\
\hline Leberzirrhose & 4 & 0 & 4 \\
\hline Sepsis & 3 & 0 & 3 \\
\hline Diabetes & 2 & 1 & 1 \\
\hline Andere Ursachen** & 9 & 4 & 5 \\
\hline
\end{tabular}

* Neunzehn Patienten verstarben an der ersten, sieben an der zweiten, zwei an der dritten und einer an der vierten akuten Pankreatitis

** Suizid (drei Patienten), alkoholinduzierte Psychose, Epilepsie, gastrointestinale Blutung, Peritonitis, multiples Organversagen, Nierenversagen (je ein Patient). 


\section{Diskussion}

\subsection{Auswirkungen verschiedener Parameter auf die Verlaufsunter- suchungen nach akuter Pankreatitis}

In jeder Studie zum natürlichen Verlauf einer akuten Pankreatitis sind folgende Probleme zu bedenken.

\subsection{1. Ätiologie}

Es ist allgemein akzeptiert, dass eine akute Pankreatitis bei Patienten mit einem Alkoholabusus als alkoholinduziert angesehen wird. Es gibt jedoch keinen Schwellenwert, $a b$ welcher Menge Alkohol und über welchen Zeitraum eine akute Pankreatitis auftritt (Durbec u. Sarles 1978). Die drei Arbeitsgruppen, die sich vor allem mit der alkoholinduzierten akuten Pankreatitis beschäftigt haben, machen unterschiedliche Angaben über den Alkoholabusus, den sie für die Entwicklung einer chronischen Pankreatitis verantwortlich machen.

- Ammann et al. (1986) gaben ähnlich wie in dieser Arbeit an, dass $>80 \mathrm{~g}$ reiner Alkohol/Tag, über mehr als fünf Jahre getrunken, zu einer akuten alkoholinduzierten Pankreatitis führt.

- Layer et al. (1994) setzten den Alkoholschwellenwert auf >50 g/Tag herab, gaben aber keine Dauer für den Alkoholabusus an.

- Gullo et al. (2002) nahmen eine alkoholinduzierte Pankreatitis an, wenn der Patient $>80 \mathrm{~g}$ Alkohol pro Tag über mehr als 5 Jahre konsumiert hatte, oder wenn ein gesellschaftlicher oder am Wochenende stattgefundener Alkoholabusus nachweisbar war.

In der hier vorgelegten Arbeit wurde ein Wert von >80 g/Tag über mindestens fünf Jahre nach Angaben des Patienten oder nach Fremdangaben gewählt, um Alkohol als Ätiologie anzunehmen. Es ist allgemeine Erfahrung, dass Patienten mit einem Alkoholabusus Menge und Zeitraum nicht immer korrekt angeben. Die Definition aller drei Gruppen - dies gilt auch für diese Untersuchung - führt daher eher zu einer Unterschätzung als 
einer Überschätzung der Anzahl von Patienten mit alkoholinduzierter Pankreatitis. Dies gilt analog auch für den Nikotinkonsum.

Wenn bei Patienten Gallensteine in der Gallenblase nachgewiesen werden, wird üblicherweise eine akute biliäre Pankreatitis angenommen. Es ist jedoch nicht sicher, ob in jedem Fall ein abgehender Gallenstein für die Erkrankung verantwortlich ist.

Ähnliches gilt für die Gruppe „andere” Ätiologie. Wenn eine akute Pankreatitis nach einer ERCP auftritt, ist die Ursache der Erkrankung mit Sicherheit diese endoskopische Maßnahme. Anders ist es beim Nachweis einer Hyperlipidämie. Sie wird zwar üblicherweise dann als Ursache der akuten Pankreatitis angenommen, wenn sich keine weiteren Ursachen finden, sicher ist dies aber nicht.

Wenn gar keine erkennbaren Ursachen vorliegen, wird routinemäßig eine idiopathische Pankreatitis bzw. eine Pankreatitis unbekannter Ätiologie angenommen. Diese Gruppe sollte den Leitlinien nach (UK Working Party on Acute Pancreatitis 2005) nicht mehr als $20 \%$ der Patienten - wie auch in dieser Studie - umfassen. Es muss jedoch offen bleiben, ob in diesen Fällen nicht doch ein - wenn auch geringer, aber Pankreatitis auslösender - Alkoholkonsum besteht oder mit einem endoskopischen Ultraschall vielleicht doch kleinste Gallensteine oder Gallengrieß hätten festgestellt werden können, die der Routineultraschalluntersuchung des Abdomens entgangen sind. Dies würde wahrscheinlich zu einer Abnahme des Anteils von Patienten mit idiopathischer Pankreatitis führen.

Für die vorliegende Studie ist dies jedoch bedeutungslos, da sich eine chronische Pankreatitis nur bei Patienten mit Alkoholabusus entwickelte.

\subsubsection{Priorität}

Es ist vielfach diskutiert worden, ob es überhaupt eine akute alkoholinduzierte Pankreatitis gibt oder ob der erste akute Schub der Erkrankung in Wirklichkeit auf dem Boden einer chronischen Pankreatitis abläuft. Zahlreiche Post-mortem-Untersuchungen haben jedoch gezeigt, dass ein Alkoholabusus zu einer akuten nekrotisierenden Pankreatitis führen kann, 
ohne dass sich im noch erhaltenen Pankreas Zeichen einer chronischen Pankreatitis zeigen (Weiner u. Tennant 1938; Clark 1942; Seligson et al. 1982; Klöppel et al. 1984; Renner et al. 1985; Schulz u. Wruck 1987).

In der hier vorgelegten Untersuchung war es ein methodisches Anliegen, alle Patienten mit unklaren früheren Schmerzattacken oder früheren oberbauchchirurgischen Eingriffen auszuschließen, sowie alle, bei denen nach Entlassung nach der ersten akuten Pankreatitis Hinweise (Kalzifikationen) auf eine chronische Pankreatitis bestanden. So sicher, wie es damit gesagt werden kann, beinhaltet diese Studie also nur Patienten mit einer ersten akuten Pankreatitis.

\subsubsection{Diagnosestellung}

Die Diagnose einer akuten Pankreatitis wird in der Regel aufgrund bildgebender Verfahren gestellt. Zwar stimmen in der Mehrzahl der Fälle die Ergebnisse von Funktionsuntersuchungen und morphologischen Verfahren, also zum Beispiel Sekretin-Pankreozymin-Test (SPT) und ERCP, überein (Lankisch et al. 1996), es gibt aber zwei größere Untergruppen: bei der einen besteht eine exokrine Pankreasinsuffizienz ohne morphologische Veränderungen, bei der anderen ist es umgekehrt. Patienten der erst genannten Gruppe entwickeln oft später Gangveränderungen und somit eine chronische Pankreatitis, bei der anderen Gruppe handelt es sich um Patienten mit einem Narbenzustand nach akuter Pankreatitis (Seidensticker et al. 1995).

Aus diesem Grund wurde analog zu dem Mayo-Clinic-Score (Layer et al. 1994) ein in Lüneburg 1986 entwickelter und 2002 (Lankisch et al. 2002) publizierter Diagnosescore gewählt, der die europäischen Untersuchungsbedingungen (Ultraschall, indirekter Pankreasfunktionstest) berücksichtigt.

Eine chronische Pankreatitis erst dann zu diagnostizieren, wenn exokrine Pankreasfunktionstests und morphologische Verfahren pathologisch waren, bedeutet, dass es sich bei der in dieser Studie beobachteten Anzahl der Patienten mit chronischer Pankreatitis eher um eine Unter- als um eine Überschätzung handelt. Eine Stärke dieser Untersuchung liegt darin, 
dass der Diagnosescore (Lankisch et al. 2002) bereits 1986 entwickelt und von da an für diese Studie prospektiv angewandt wurde.

In den beiden anderen Untersuchungen wurden retrospektiv Patienten eingeschlossen, die von früheren Ärztegruppen nach anderen Diagnosekriterien beurteilt wurden (Ammann et al. 1986; Layer et al. 1994).

\subsubsection{Nachuntersuchungen}

Analog zur Mayo-Clinic (Layer et al. 1994) wurden in dieser Studie die Auswertung späterer stationärer Aufenthalte sowie die Ergebnisse der telefonischen und schriftlichen Befragungen von Patienten und ihren Hausärzten für die Nachuntersuchung benutzt. Erneut stellt sich die Frage nach der Aufrichtigkeit der Patienten hinsichtlich ihrer Angaben.

Ein besseres Bild über den Verlauf der Erkrankung ließe sich durch regelmäßige Nachuntersuchungen der betroffenen Patienten im Krankenhaus gewinnen, wie dies in der Schweizer Untersuchung (Ammann et al. 1986) geschehen ist. Solche Nachuntersuchungen sind jedoch in Deutschland und wohl auch in anderen Ländern nicht möglich, da asymptomatische Patienten nicht ins Krankenhaus zu intensiven Untersuchungen im regelmäßigen Intervall überwiesen werden.

\subsubsection{Rezidivrate}

Anders als in der hier vorgelegten Untersuchung ist ein Rezidiv einer biliären akuten Pankreatitis heutzutage selten, weil in der Regel eine Cholezystektomie noch vor der Entlassung des Patienten erfolgt. Die in dieser Untersuchung beobachtete relativ hohe Rezidivrate erklärt sich dadurch, dass einigen Patienten eine Cholezystektomie noch während des ersten stationären Aufenthaltes nicht empfohlen wurde oder dass die Patienten diese Empfehlung ablehnten.

Die Rezidivrate von $12 \%$ bei nicht cholezystektomierten Patienten entspricht übrigens in etwa den Angaben einer dänischen Untersuchung (Lund et al. 2006). 


\subsection{Entwicklung einer chronischen Pankreatitis}

\subsubsection{Einfluss eines Alkoholabusus}

In der hier vorgelegten Untersuchung wurden folgende Ergebnisse erzielt:

- Eine chronische Pankreatitis entwickelte sich nur bei $4 \%$ aller Patienten nach einer ersten akuten Bauchspeicheldrüsenentzündung. Dies entspricht den Angaben beider Marseille-Klassifikationen (Sarles 1965; Singer et al. 1985) und einer Studie der Marseiller Gruppe (Sarles et al. 1965), die zeigte, dass die Entwicklung einer chronischen Pankreatitis nach einer akuten Pankreatitis zwar möglich, aber relativ selten ist.

- Eine Progression von akuter zu chronischer Pankreatitis trat nur bei Patienten mit einer ersten alkoholinduzierten Pankreatitis auf. Lediglich ein Patient, bei dem die erste akute Pankreatitis auf einen Lupus erythematodes zurückgeführt wurde ("andere Ursachen"), entwickelte eine chronische Pankreatitis. Dieser Patient begann aber nach der ersten akuten Pankreatitis mit einem erheblichen Alkoholkonsum und wurde daher - wie bereits erwähnt (S. 25) - in die "Alkohol"-Gruppe aufgenommen.

- Alle Patienten, die in der hier vorgelegten Untersuchung eine chronische Pankreatitis entwickelten, waren schwere Alkoholiker. Das scheint im Widerspruch zu der geläufigen Ansicht zu stehen, dass eine chronische Pankreatitis nur aufgrund multipler ätiologischer Faktoren entsteht. Viele dieser ätiologischen Faktoren sind selten, wie zum Beispiel eine hereditäre oder eine Autoimmunpankreatitis. Es ist daher unwahrscheinlich, dass sie in einer populationsbasierten Untersuchung wie dieser überhaupt beobachtet werden (Etemad u. Whitcomb 2001).

- Bei Patienten mit einer ersten alkoholinduzierten akuten Pankreatitis entwickelte sich die chronische Form der Erkrankung innerhalb von zehn bzw. 20 Jahren in 13\% bzw. 16\% der Fälle. Die Häufigkeit einer chronischen Pankreatitis betrug jedoch $38 \%$ bereits nach zwei Jahren und $41 \%$ nach zehn Jahren, wenn schon ein Rezidiv aufgetreten war. 
Auffällig war der kurze Zeitraum zwischen dem ersten Rezidiv und der späteren Entwicklung einer chronischen Pankreatitis.

Die hier vorgelegten Ergebnisse stehen im Widerspruch zu einigen früheren Untersuchungen anderer Autoren:

- Ammann et al. (1986) beobachteten die Entwicklung einer chronischen Pankreatitis bei 95 (66\%) von 144 Patienten innerhalb von $91 / 2$ Jahren. Diese Ergebnisse wurden allerdings in einem auf Pankreaserkrankungen spezialisierten Universitätszentrum erhoben. Möglicherweise erklärt ein Selektionsbias in diesem Zentrum die Unterschiede zu den hier vorgelegten Ergebnissen, die in einem kommunalen Krankenhaus erzielt wurden.

- Skinazi et al. (1995) berichteten in einer französischen Studie, dass 89\% der Patienten mit einer akuten alkoholinduzierten Pankreatitis die chronische Form der Erkrankung innerhalb von zwei Jahren entwickelten. In der hier vorgelegten Untersuchung waren es deutlich weniger. Auch hier gilt die Annahme eines Selektionsbias wie bei der französischen Untersuchung, da die Untersuchungen ebenfalls in einem auf Pankreaserkrankungen spezialisierten Zentrum durchgeführt wurden.

- Nach einer ersten akuten idiopathischen Bauchspeicheldrüsenentzündung muss es, wie die hier vorgelegte Untersuchung zeigt, trotz einer hohen Rezidivrate von 14\%, nicht zwangsläufig zu einer chronischen Pankreatitis kommen. Das bedeutet, dass einige Patienten mit einer chronischen idiopathischen Pankreatitis diese Erkrankung entwickelt haben, ohne dass bei ihnen eine gut dokumentierte erste akute Pankreatitis nachgewiesen wurde.

Dieses Ergebnis steht im Widerspruch zu einer Studie aus Indien, die berichtete, dass es bei $47 \%$ der Patienten mit idiopathischer akuter Pankreatitis zu der chronischen Form der Erkrankung kam (Garg et al. 2007). Diese unterschiedlichen Ergebnisse könnten auf nationalen Unterschieden beruhen. 


\subsubsection{Einfluss eines Nikotinabusus}

In der hier vorgelegten Untersuchung führte starker Zigarettenkonsum sowohl zu einer erhöhten Rezidivrate als auch zu einer chronischen Pankreatitis. Fast alle Patienten in der Schweizer Untersuchung (Ammann et al. 1986) waren übrigens auch starke Raucher (Maisonneuve et al. 2006).

Es ist allgemein bekannt, dass Alkohol ein Hauptfaktor für die Entwicklung einer chronischen Pankreatitis ist. In der hier vorgelegten Untersuchung wird jedoch deutlich hervorgehoben, dass Rauchen ein zweiter wesentlicher, so genannter Lebensstilfaktor ist, was bereits in früheren Untersuchungen anderer Autoren zum Ausdruck kam (Talamini et al. 1999; Lin et al. 2000; Maisonneuve et al. 2005; Wittel et al. 2006). Es kommt also darauf an, die Patienten zu überzeugen, beide Risikofaktoren zu vermeiden, wodurch sich signifikant die Wahrscheinlichkeit reduzieren würde, eine chronische Pankreatitis zu entwickeln, eine Erkrankung, für die es zur Zeit nur sehr wenige Behandlungsmöglichkeiten gibt.

\subsection{Letalität}

Nach den Ergebnissen der hier vorgelegten Untersuchung verstarben während der gesamten Nachuntersuchungsperiode nach der ersten akuten Pankreatitis 143 Patienten. Insgesamt 29 (20\%) der Todesfälle waren auf die Pankreatitis zurückzuführen. Bereits während der ersten akuten Attacke verstarben 19 Patienten.

Andere Haupttodesursachen waren kardio- bzw. zerebrovaskuläre oder pulmonale Erkrankungen, die mit Nikotinabusus verbunden waren, während weitere Todesursachen, wie Leberzirrhose oder eine akute Alkoholpsychose, im direkten Zusammenhang mit einem Alkoholabusus standen.

Vier Patienten verstarben an einem Pankreaskarzinom. Obwohl das Pankreaskarzinomrisiko bei Patienten mit chronischer und hereditärer Pankreatitis erhöht ist (Lowenfels et al. 1993, 1997), entwickelten diese vier Patienten ein Pankreaskarzinom, ohne dass es Hinweise auf eine chronische Pankreatitis gab. 


\subsection{Schlussfolgerung}

Unabhängig von der Ätiologie der ersten akuten Pankreatitis erlitten in dieser populationsbasierten Untersuchung 88 (18\%) von 501 nachverfolgten Patienten ein Pankreatitisrezidiv. Bei $4 \%$ von innen entwickelte sich allmählich die chronische Form der Erkrankung, so weit dies anhand klinischer Untersuchungen sowie Ergebnissen von funktionellen und bildgebenden Verfahren zu beurteilen war. Es muss offen bleiben, ob und in welchem Maße klinisch stumme Verläufe auftraten. Es muss ferner offen bleiben, ob die Patienten, die ein Pankreatitisrezidiv hatten, jedoch nicht die chronische Form der Erkrankung entwickelten, einen besonderen Schutzmechanismus besitzen oder ob in diesen Fällen der Beobachtungszeitraum zu kurz war.

Das Fortschreiten einer akuten zu einer chronischen Pankreatitis wurde nur bei Patienten mit einem regelmäßigen erheblichen Alkoholkonsum beobachtet. Das Schicksal, eine chronische Pankreatitis zu entwickeln, ist aber selbst beim Alkoholiker nicht unvermeidbar. Das Risiko erhöht sich jedoch erheblich bei Patienten mit einem ersten Rezidiv der Erkrankung und ist assoziiert mit einem Nikotinabusus. Spätestens zu diesem Zeitpunkt sollten Präventionsmaßnahmen einsetzen, um eine Einstellung von Nikotin- und Alkoholabusus zu erreichen. Ob diese Maßnahmen jedoch das Fortschreiten von einer akuten zu einer chronischen Pankreatitis verhindern können, muss durch weitere Untersuchungen geklärt werden. 


\section{Zusammenfassung}

1. Ziel dieser Untersuchung war es, festzustellen, ob eine akute Pankreatitis folgenlos ausheilt oder ob, und unter welchen Bedingungen, die Erkrankung in eine chronische Pankreatitis übergeht.

2. Die Untersuchung umfasste 532 Patienten. Die Ätiologie war bei 224 (42\%) Patienten biliär, bei 158 (30\%) alkoholisch und bei 106 (20\%) unbekannt. In $44(8 \%)$ Fällen wurden andere Ursachen angenommen. Von den 532 Patienten verstarben $19(4 \%)$ an den Folgen der ersten akuten Pankreatitis und zwölf (2\%) konnten nicht nachverfolgt werden. Somit standen für diese Untersuchung insgesamt 501 (98\%) der 513 überlebenden Patienten zur Verfügung.

3. Zu einem ersten Rezidiv der Erkrankung kam es bei 88 (18\%), zu einem zweiten bei $31(6 \%)$ und zu drei und mehr Rezidiven bei zwölf (2\%) Patienten. Rezidive waren bei Patienten mit alkoholinduzierter Pankreatitis signifikant häufiger als in den anderen ätiologischen Gruppen.

4. Die Diagnose einer chronischen Pankreatitis wurde aufgrund eines 1986 festgelegten Punktebewertungssystems (Lüneburg-Score) gestellt, der ähnlich wie der Mayo-Clinic-Score die Diagnose der chronischen Form der Erkrankung nur dann zulässt, wenn pathologische Ergebnisse von Funktions- und morphologischen Untersuchungen vorliegen. Die Diagnose galt darüber hinaus als gesichert, wenn Pankreasverkalkungen als Zeichen einer chronischen Pankreatitis nachweisbar waren.

5. Unter Anwendung dieses Punktebewertungssystems wurde 1987 bis 2004 (mittlere Nachverfolgungszeit 7,8 \pm 5,3 Jahre) bei 19 (4\%) von 501 Patienten die Diagnose einer chronischen Pankreatitis gestellt. Achtzehn von ihnen waren Alkoholiker, ein Patient mit einer ersten akuten Pankreatitis anderer Ätiologie begann anschließend mit einem erheblichen Alkoholabusus, so dass auch er in die Gruppe der Alkoholiker aufgenommen wurde. Insgesamt lag das Zeitintervall zwischen der ersten Pankreatitis und der Diagnose der chronischen Form der Erkran- 
kung bei $3 \pm 7$ Jahren ( 4 Monate bis 16 Jahre). Die Diagnose wurde bei neun Patienten beim ersten, bei sieben beim zweiten und bei drei beim dritten Rezidiv gestellt.

6. Die Häufigkeit einer chronischen Pankreatitis in der Patientengruppe mit alkoholinduzierter Pankreatitis lag nach zehn bzw. 20 Jahren bei $13 \%$ bzw. 16\%. Die Häufigkeit stieg deutlich nach dem ersten Rezidiv der Erkrankung an: sie betrug 38\% bereits nach zwei bzw. $41 \%$ nach zehn Jahren.

7. Ein Nikotinabusus trug vermehrt zur Entwicklung einer chronischen Pankreatitis bei.

8. Insgesamt verstarben 124 (25\%) der Patienten im Verlauf der Nachbeobachtungszeit. Ein Unterschied zwischen den ätiologischen Gruppen bestand nicht.

9. Eine chronische Pankreatitis entwickelte sich nur bei Patienten mit einer alkoholinduzierten Pankreatitis, wobei die Häufigkeit durch Nikotinabusus noch erhöht wurde. Diese Entwicklung trifft jedoch nicht jeden Patienten mit einer alkoholinduzierten Pankreatitis. Es erscheint vorstellbar, dass eine durch intensive Präventionsmaßnahmen zu erreichende Alkohol- und Nikotinabstinenz diese Entwicklung aufhalten kann. 


\section{Anhang}

\section{FRAGEBOGEN}

\section{zu Ihrem Befinden nach der ersten akuten Bauchspeicheldrüsenentzündung}

Angaben zur Person

- Name

- Geburtsdatum

- Jetziger Hausarzt

Familienvorgeschichte

Hat jemals ein Familienangehöriger eine akute Pankreatitis

durchgemacht? Nein / Ja / Mir nicht bekannt

Wenn ja, wer?

Hat jemals ein Familienangehöriger einen Bauchspeichel-

drüsenkrebs gehabt? Nein / Ja / Mir nicht bekannt

Wenn ja, wer?

Hat jemals ein Familienangehöriger eine Mukoviszidose

(zystische Fibrose) durchgemacht? Nein / Ja / Mir nicht bekannt

Wenn ja, wer?

- Hat jemals ein Familienangehöriger eine Zuckerkrankheit

(Diabetes mellitus) durchgemacht? Nein / Ja / Mir nicht bekannt

Wenn ja, wer?

Gegenwärtiger Zustand

Haben Sie Bauchschmerzen?

Nein / Ja

Wenn ja, wo? Oberbauch / Mittelbauch / Unterbauch, rechts / links Wenn ja, wie oft? $\quad$..... am Tag / ..... in der Woche / ..... im Monat

Wenn ja, bitte geben Sie mit einer Zahl von $0-10$ an, wie stark Sie die

Schmerzen empfinden ( $0=$ kein Schmerz, $10=$ maximaler Schmerz)

Wie oft am Tag haben Sie Stuhlgang?

Nicht tägl. / tägl. 1 x / tägl. 2 x / tägl. 3 x / mehr

Wenn ja, wer hat behandelt?

Ist bei Ihnen eine Zuckerkrankheit seit der ersten akuten

Bauchspeicheldrüsenentzündung festgestellt worden? Nein / Ja

Wenn ja, wann? 
Haben Sie einen Gewichtsverlust bemerkt im Vergleich zu der Zeit vor der ersten Bauchspeicheldrüsenentzündung?

Wenn ja, wie viel Kilogramm?

Haben Sie seit der ersten Bauchspeicheldrüsenentzündung weitere Entzündungen gehabt?

Wenn ja, wie oft?

Wenn ja, wann (Datum)?

Wenn ja, welches Krankenhaus?

Wurde eine Gallenblasenentfernung (Cholezystektomie)

durchgeführt?

Nein / Ja

Wenn ja, wann (Datum)?

Wenn ja, welches Krankenhaus?

Wurden andere Operationen in der Zwischenzeit bei Ihnen

durchgeführt?

Nein / Ja

Wenn ja, welche Operation?

Wenn ja, wann (Datum)?

Wenn ja, welches Krankenhaus?

Haben Sie nach Ihrer ersten akuten Bauchspeicheldrüsenentzündung andere Erkrankungen durchgemacht?

Nein / Ja

Wenn ja, welche?

Haben Sie vor der ersten Bauchspeicheldrüsenentzündung geraucht?

Nein / Ja

Wenn ja, wie viele Zigaretten / Zigarren / Pfeifen pro Tag?

Rauchen Sie jetzt?

Nein / Ja

Wenn ja, wie viele Zigaretten / Zigarren / Pfeifen pro Tag?

Haben Sie vor der ersten Bauchspeicheldrüsenentzündung

Alkohol getrunken?

Nein / Ja

Wenn ja:

Glas Bier / Flaschen Bier (0,33 I) / Glas Wein

Glas Schnaps / Cognac, etc. /

Glas eines anderen alkoholischen Getränks (welches)

\section{Täglich / pro Woche}

Trinken Sie zur Zeit Alkohol?

Nein / Ja

Wenn ja: 
Glas Bier / .

Flaschen Bier (0,33 I) /

Glas Wein

Glas Schnaps / Cognac, etc. /

Glas eines anderen alkoholischen Getränks (welches)

Täglich / pro Woche

Ich habe den Fragebogen selbst ausgefüllt

Nein / Ja

Wenn nein, wer hat es für Sie getan? Verwandter / Freund

Datum

Unterschrift 


\section{Literaturverzeichnis}

Ammann RW, Buehler H, Bruehlmann W, Kehl O, Muench R, Stamm B (1986): Acute (nonprogressive) alcoholic pancreatitis: prospective longitudinal study of 144 patients with recurrent alcoholic pancreatitis. Pancreas 1: 195-203

Balthazar EJ, Ranson JHC, Naidich DP, Megibow AJ, Caccavale R, Cooper MM (1985): Acute pancreatitis: prognostic value of CT. Radiology 156: 767-772

Balthazar EJ, Robinson DL, Megibow AJ, Ranson JHC (1990): Acute pancreatitis: value of CT in establishing prognosis. Radiology 174: 331-336

Blamey SL, Imrie CW, O'Neill J, Gilmour WH, Carter DC (1984): Prognostic factors in acute pancreatitis. Gut 25: 1340-1346

Bradley III EL (1993): A clinically based classification system for acute pancreatitis. Summary of the International Symposium on Acute Pancreatitis, Atlanta, Ga, September 11 through 13, 1992. Arch Surg 128: 586-590

Clark E (1942): Pancreatitis in acute and chronic alcoholism. Am J Dig Dis 9: $428-431$

Creutzfeldt W (1964): Funktionsdiagnostik bei Erkrankungen des exokrinen Pankreas. Verh Dtsch Ges Inn Med 70: 781-801

Durbec JP, Sarles H (1978): Multicenter survey of the etiology of pancreatic diseases. Relationship between the relative risk of developing chronic pancreatitis and alcohol, protein and lipid consumption. Digestion 18: 337-350

Etemad B, Whitcomb DC (2001): Chronic pancreatitis: diagnosis, classification, and new genetic developments. Gastroenterology 120: $682-707$

Garg PK, Tandon RK, Madan K (2007): Is biliary microlithiasis a significant cause of idiopathic recurrent acute pancreatitis? A long-term followup study. Clin Gastroenterol Hepatol $\underline{5}$ : 75-79 
Gullo L, Migliori M, Oláh A, Farkas G, Levy P, Arvanitakis C, Lankisch P, Beger H (2002): Acute pancreatitis in five European countries: etiology and mortality. Pancreas 24: 223-227

Hanck C, Singer MV (1997): Does acute alcoholic pancreatitis exist without preexisting chronic pancreatitis? Scand J Gastroenterol 32: 625-626

Imrie CW, Benjamin IS, Ferguson JC, McKay AJ, Mackenzie I, O'Neill J, Blumgart LH (1978): A single-centre double-blind trial of Trasylol therapy in primary acute pancreatitis. $\mathrm{Br}]$ Surg 65: 337-341

Klöppel G (1999): Progression from acute to chronic pancreatitis. A pathologist's view. Surg Clin North Am 79: 801-814

Klöppel G, von Gerkan R, Dreyer T: Pathomorphology of acute pancreatitis. Analysis of 367 autopsy cases and 3 surgical specimens; in: Pancreatitis. Concepts and classification. Proceedings of the 2nd International Symposion on the Classification of Pancreatitis, Marseilles, France, 1984; hrsg. v. Gyr KE, Singer MV, Sarles H. Excerpta Medica, Amsterdam-New York-Oxford 1984, 2935

Knaus WA, Draper EA, Wagner DP, Zimmerman JE (1985): APACHE II: a severity of disease classification system. Crit Care Med 13: 818-829 Lankisch PG (1999): Progression from acute to chronic pancreatitis. A physician's view. Surg Clin North Am 79: 815-827

Lankisch PG: Pancreolauryl-Test; in: Labor und Diagnose. Indikation und Bewertung von Laborbefunden für die medizinische Diagnostik; hrsg. v. Thomas L. TH-Books Verlagsges. mbH, Frankfurt/Main 2005, 635-636

Lankisch PG, Seidensticker F, Otto J, Lübbers H, Mahlke R, Stöckmann F, Fölsch UR, Creutzfeldt W (1996): Secretin-pancreozymin test (SPT) and endoscopic retrograde cholangiopancreatography (ERCP): both are necessary for diagnosing or excluding chronic pancreatitis. Pancreas 12: 149-152 
Lankisch PG, Mahlke R, Blum T, Bruns A, Bruns D, Maisonneuve P, Lowenfels $A B$ (2001): Hemoconcentration: an early marker of severe and/or necrotizing pancreatitis? A critical appraisal. Am J Gastroenterol 96: 2081-2085

Lankisch PG, Assmus C, Maisonneuve P, Lowenfels AB (2002):

Epidemiology of pancreatic diseases in Lüneburg County - A study in a defined German population. Pancreatology 2: 469-477

Layer P, Yamamoto H, Kalthoff L, Clain JE, Bakken L, DiMagno EP (1994):

The different courses of early- and late-onset idiopathic and alcoholic chronic pancreatitis. Gastroenterology 107: 1481-1487

Lin Y, Tamakoshi A, Hayakawa T, Ogawa M, Ohno Y, The Research Committee on Intractable Pancreatic Diseases (2000): Cigarette smoking as a risk factor for chronic pancreatitis: a case-control study in Japan. Pancreas 21: 109-114

Lowenfels AB, Maisonneuve P, Cavallini G, Ammann RW, Lankisch PG, Andersen JR, DiMagno EP, Andrén-Sandberg $\AA$, Domellöf $L$, International Pancreatitis Study Group (1993): Pancreatitis and the risk of pancreatic cancer. N Engl J Med 328: 1433-1437

Lowenfels AB, Maisonneuve P, DiMagno EP, Elitsur Y, Gates LK, Jr., Perrault J, Whitcomb DC, International Hereditary Pancreatitis Study Group (1997): Hereditary pancreatitis and the risk of pancreatic cancer. J Natl Cancer Inst 89: 442-446

Lund $\mathrm{H}$, Tønnesen $\mathrm{MH}$, Olsen $\mathrm{O}$ (2006): Long-term recurrence and death rates after acute pancreatitis. Scand J Gastroenterol 41: 234-238 Maisonneuve P, Lowenfels AB, Müllhaupt B, Cavallini G, Lankisch PG, Andersen JR, DiMagno EP, Andrén-Sandberg $\AA$, Domellöf L, Frulloni L, Ammann RW (2005): Cigarette smoking accelerates progression of alcoholic chronic pancreatitis. Gut 54: 510-514 Maisonneuve P, Frulloni L, Müllhaupt B, Faitini K, Cavallini G, Lowenfels $A B, A m m a n n$ RW (2006): Impact of smoking on patients with idiopathic chronic pancreatitis. Pancreas 33: 163-168 Mallory A, Kern F (1980): Drug-induced pancreatitis: a critical review. Gastroenterology 78: 813-820 
Mallory A, Kern F (1988): Drug-induced pancreatitis. Baillière Clin Gastroenterol 2: 293-307

Ranson JHC (1982): Etiological and prognostic factors in human acute pancreatitis: a review. Am J Gastroenterol 77: 633-638

Ranson JHC, Rifkind KM, Roses DF, Fink SD, Eng K, Spencer FC (1974):

Prognostic signs and the role of operative management in acute pancreatitis. Surg Gynecol Obstet 139: 69-81

Renner IG, Savage III WT, Pantoja JL, Renner VJ (1985): Death due to acute pancreatitis. A retrospective analysis of 405 autopsy cases. Dig Dis Sci 30: 1005-1018

Sarles H: Proposal adopted unanimously by the participants of the Symposium, Marseilles 1963; in: Pancreatitis. Bibl. Gastroenterol. 7; hrsg. v. Sarles H. Karger, Basel-New York 1965, VII-VIII

Sarles H, Sarles J-C, Camatte R, Muratore R, Gaini M, Guien C, Pastor J, Le Roy $F$ (1965): Observations on 205 confirmed cases of acute pancreatitis, recurring pancreatitis, and chronic pancreatitis. Gut $\underline{6}$ : 545-559

Sarles H, Adler G, Dani R, Frey C, Gullo L, Harada H, Martin E, Norohna M, Scuro LA (1989): The pancreatitis classification of Marseilles-Rome 1988. Scand J Gastroenterol 24: 641-642

Sarner M, Cotton PB (1984a): Classification of pancreatitis. Gut 25: 756759

Sarner M, Cotton PB (1984b): Definitions of acute and chronic pancreatitis. Clin Gastroenterol 13: 865-870

Schulz H-J, Wruck U (1987): Zu Todesursachen und einigen ätiologischen Aspekten der akuten und chronischen Pankreatitis. Dtsch Z Verdau Stoffwechselkr 47: 33-38

Seidensticker F, Otto J, Lankisch PG (1995): Recovery of the pancreas after acute pancreatitis is not necessarily complete. Int J Pancreatol 17: $225-229$

Seligson U, Cho J-W, Ihre T, Lundh G (1982): Clinical course and autopsy findings in acute and chronic pancreatitis. Acta Chir Scand 148: 
Singer MV, Gyr K, Sarles H (1985): Revised classification of pancreatitis. Report of the Second International Symposium on the Classification of Pancreatitis in Marseille, France, March 28-30, 1984.

Gastroenterology 89: 683-685

Skinazi F, Lévy P, Bernades P (1995): Les pancréatites aiguës alcooliques révèlent-elles toujours une pancréatite chronique? Gastroenterol Clin Biol 19: 266-269

Talamini G, Bassi C, Falconi M, Sartori N, Salvia R, Rigo L, Castagnini A, Di Francesco V, Frulloni L, Bovo P, Vaona B, Angelini G, Vantini I, Cavallini G, Pederzoli P (1999): Alcohol and smoking as risk factors in chronic pancreatitis and pancreatic cancer. Dig Dis Sci 44: 13031311

Trivedi CD, Pitchumoni CS (2005): Drug-induced pancreatitis. An update. J Clin Gastroenterol 39: 709-716

UK Working Party on Acute Pancreatitis (2005): UK guidelines for the management of acute pancreatitis. Gut 54 (suppl III): iii1-iii9. doi: 101136/gut.2004.057026

Van de Kamer JH, ten Bokkel Huinink H, Weyers HA (1949): Rapid method for the determination of fat in feces. J Biol Chem 177: 347-355 Weiner HA, Tennant RA (1938): A statistical study of acute hemorrhagic pancreatitis (hemorrhagic necrosis of pancreas). Am J Med Sci 196: 167-176

Wittel UA, Pandey KK, Andrianifahanana M, Johansson SL, Cullen DM, Akhter MP, Brand RE, Prokopczyk B, Batra SK (2006): Chronic pancreatic inflammation induced by environmental tobacco smoke inhalation in rats. Am J Gastroenterol 101: 148-159 


\section{Danksagung}

Mein besonderer Dank gilt Herrn Professor Dr. med. Paul Georg Lankisch für die Überlassung des Themas und für seine unbegrenzte Unterstützung und Geduld mit mir. Besonders hilfreich waren seine ständige Bereitschaft und sein offenes Ohr für die Fragen und Probleme, die sich immer wieder aufwarfen, sowie seine umfassende Betreuung, die Bereitstellung von Literatur und die zahlreichen konstruktiven Vorschläge zur Korrektur dieser Arbeit, und vor allem seine mir geopferte Zeit.

Ganz besonders hervorzuheben ist auch Patrick Maisonneuve, der mich wesentlich bei der Erstellung der Statistik unterstützte. Vielen Dank nach Mailand!

Daneben möchte ich allen meinen Kollegen der Arbeitsgruppe für die freundschaftliche Unterstützung und Zusammenarbeit danken, hier vor allem Anja Bruns, Bettina Dany-Weber, Kerstin Krieger und Gisela Ropte. 


\section{Lebenslauf}

Am 22.05.1977 wurde ich in Freiburg i. Br. als zweiter Sohn von Wulf und Renate Breuer geboren, wuchs in Lampertheim auf und wurde dort 1983 eingeschult.

Im Jahr 1987 wechselte ich auf das Albertus-Magnus-Gymnasium in Viernheim. Dort erlangte ich 1996 mit den Leistungskursen Mathematik und Physik das Abitur und trat als Sanitätsoffiziersanwärter der Bundeswehr in den Sanitätsdienst der Marine ein.

Im Rahmen der Offiziersausbildung nahm ich im Herbst 1996 an einer dreimonatigen Seefahrt auf dem Segelschulschiff "Gorch-Fock" teil.

Zum Sommersemester 1997 begann ich das Humanmedizinstudium in Göttingen. Dort bestand ich 1999 das Physikum, im Jahr 2000 das 1. Staatsexamen und im Jahr 2002 das 2. Staatsexamen.

Im Anschluss daran wechselte ich an das Städtische Klinikum Lüneburg (Akademisches Lehrkrankenhaus der Universität Göttingen), um dort mein Praktisches Jahr in den Fächern Innere Medizin unter Professor Dr. Lankisch, Chirurgie unter Professor Dr. Schafmayer und dem Wahlfach Radiologie unter der Leitung von Professor Dr. Brinkmann zu absolvieren.

Im Jahr 2003 schloss ich das Humanmedizinstudium mit dem 3. Staatsexamen ab.

Danach nahm ich meine Tätigkeit als AiP auf der Station IX (Orthopädie) des Bundeswehrkrankenhauses Hamburg (Abteilungsleiter OTA Dr. Niehaus) auf und rotiere seitdem über die Abteilungen des Bundeswehrkrankenhauses, um den Facharzt für Allgemeinmedizin zu erlangen.

Im August 2004 übernahm ich die Position des Leiters Medizincontrolling des Bundeswehrkrankenhauses Hamburg im Nebenamt. Seit März 2007 studiere ich berufsbegleitend an der Universität Hamburg den Masterstudiengang „Gesundheits- und Sozialmanagement" (MBA). 